Submitted to Metallurgical and Materials Transaction B on June 13 2005, and revised on November11,2005

\title{
INVESTIGATION OF FLUID FLOW AND STEEL CLEANLINESS IN THE CONTINUOUS CASTING STRAND
}

\author{
Authors: \\ Prof. Lifeng Zhang (Correspondence author) \\ Department of Materials Science and Engineering \\ Norwegian University of Science and Technology (NTNU) \\ Høgskoleringen 8, Alfred Getz vei2 \\ 7491 Trondheim, Norway. \\ Tel: 0047-73594123 Fax: 0047-73550203 \\ Email: lifeng.zhang@material.ntnu.no \\ Dr. Subo Yang \\ Technical Research Center, Panzhihua Iron and Steel Company \\ Panzhihua, Sichuan Province, P.R.China
}

Prof. Kaike Cai, Mr. Jiying Li, Mr. Xiaoguang Wan

School of Metallurgy, University of Science \& Technology Beijing

Beijing 100083, P.R.China

Prof. Brian G. Thomas

Department of Mechanical and Industrial Engineering

University of Illinois at Urbana-Champaign

1206 W. Green St., Urbana, IL 61801, USA

Phone number: 1-217-333-6919

Fax number: 1-217-244-6534

Email: bgthomas@uiuc.edu 


\begin{abstract}
:
Fluid flow in the mold region of the continuous slab caster at Panzhihua Steel is investigated with 0.6-scale water model experiments, industrial measurements, and numerical simulations. In the water model, multiphase fluid flow in the submerged entry nozzle (SEN) and the mold with gas injection is investigated. Top surface level fluctuations, pressure at the jet impingement point, and the flow pattern in the mold are measured with changing submergence depth ,SEN geometry, mold width, water flow rate, and argon gas flow rate. In the industrial investigation, the top surface shape and slag thickness are measured, and steel cleanliness including inclusions and the total oxygen content are quantified and analyzed, comparing the old and new nozzle designs. Three kinds of fluid flow pattern are observed in the SEN: bubbly flow, annular flow, and an intermediate critical flow structure. The annular flow structure induces detrimental asymmetrical flow and worse level fluctuations in the mold.. The SEN flow structure depends on the liquid flow rate, the gas flow rate, and the liquid height in the tundish. The gas flow rate should be decreased at low casting speed in order to maintain stable bubbly flow, which produces desirable symmetrical flow. Two main flow patterns are observed in the mold: single roll and double roll. The single roll flow pattern is generated by large gas injection, small SEN submergence depth and low casting speed. To maintain a stable double-roll flow pattern, which is often optimal, the argon should be kept safely below a critical level. The chosen optimal nozzle had $45 \mathrm{~mm}$ inner bore diameter, downwards $15^{\circ}$ port angle, 2.27 port-to-bore area ratio, and a recessed-bottom. The pointed bottom SEN generates smaller level fluctuations at the meniscus, larger impingement pressure, deeper impingement, and more inclusion entrapment in the strand than the recess-bottom SEN. Mass balances of inclusions in the steel slag from slag and slab measurements shows that around $20 \%$ of the alumina inclusions are removed from the steel into the mold slag. However, entrainment of the mold slag itself is a critical problem. Inclusions in the steel slabs increase two-fold during ladle changes and ten-fold during the start and end of a sequence. All the findings in the current study are important for controlling slag entrainment.
\end{abstract}

\title{
Key Words:
}

Continuous Casting, SEN, Mold, Fluid flow, Level Fluctuation, Water Model, Inclusions, Total Oxygen, Industrial Investigation, Slag Entrainment 


\section{INTRODUCTION}

Fluid flow in the Submerged Entry Nozzle (SEN) and the continuous casting mold is important due to its effect on many phenomena related to the steel quality, such as the transport of argon bubbles and inclusions, transient waves and fluctuations of the top surface, the transport of superheat, meniscus freezing, shell thinning from the jet impinging upon the solidifying shell, thermal stress and crack formation. The entrainment of mold slag due to excessive surface velocities and level fluctuations is one of the most important causes of defects found in steel products. ${ }^{[1-9]}$

The main flow-related phenomena that cause slag entrainment and surface quality problems are shown in Figure $1^{[10]}$. If the jet from the SEN outport strongly impinges on the narrow face and splits to flows upwards along the narrow face, it will lift the level of the molten steel, changing its profile, and also generating large level fluctuations near the meniscus. This also pushes slag away from the narrow face, leading to surface quality problems. ${ }^{[10-17]}$ Direct jet impingement of the jet onto the steel-slag interface associated with a single roll flow pattern, such as induced by excessive gas bubble injection, ${ }^{[18]}$ is even more detrimental. Excessive velocity of the molten steel across the top surface may shear off fingers of slag into the steel ${ }^{[19-27]}$ Turbulence and level fluctuations at the top surface can induce slag entrainment at the meniscus, and surface defects. Flow problems such as uneven flow discharge from opposite ports of the $\mathrm{SEN}^{[10]}$, may cause asymmetric and unsteady flow in the mold, ${ }^{[28]}$ and / or periodic oscillations of the level. High speed surface flows or asymmetrical flow in the mold may also induce vortices near the SEN, ${ }^{10,}$

29]. These are other important causes of slag entrainment. Emulsification of the slag / steel interface, such as caused by the rupture of bubbles floating to this interface ${ }^{[16,30]}$ is also dangerous. The slag foam is easily entrained into the steel flow. Alternatively, slag may be sucked down along the SEN wall due to flow recirculation and the low pressure region just above the SEN port exits. ${ }^{[10]}$ Mold slag may enter the upper portion of the ports and cause clogging problems, or become entrained into the jet, and cause serious slag entrainment problems. Thus, the fluid flow pattern in the mold and level fluctuations are of great importance to slag entrainment quality problems, ${ }^{[21]}$ and large level fluctuations correlate with more surface defects in the steel product. ${ }^{[2]}$ 
In the current paper, fluid flow in the SEN and the mold of the slab continuous caster at Panzhihua Steel (P.R.China) is investigated using water models, numerical simulations and industrial measurements. First, the water model is used to investigate the fluid flow pattern in the SEN, which is one of the sources of asymmetrical flow in the mold. Then, flow in the mold is quantified by measuring the magnitude of the top surface level fluctuations, the pressure near the jet impingement point on the narrow face, and the flow pattern shape for different SEN geometry, submergence depth, mold width, water flow rate, and gas flow rate. The single roll and double roll flow pattern, and the top surface emulsification induced by bubbles are noted. In the mathematical simulation, three-dimensional fluid flow and particle transport are calculated in the water model of the tundish, the SEN and the mold. In the industrial trial, the thickness of the liquid slag layer, and the inclusion content in the steel and slag are measured, to determine the extent of inclusion removal in the mold, relative to inclusions entrapped in the steel product. The effect of the SEN well shape on steel cleanliness is also investigated. Finally, improved design and operating conditions are chosen to improve fluid flow and steel cleanliness in the plant.

\section{INVESTIGATION METHODS}

\section{A. Similarity Criterion of Water Model experiments}

Extensive past work has employed physical water models to investigate fluid flow phenomena in the mold region of the continuous casting process. ${ }^{[19,31-46]}$ The first study was carried out by Afanaseva et al ${ }^{[31]}$ for a straight bore nozzle system. Heaslip et al extensively studied the fluid flow in SENs under stopper-rod control and slide-gate control ${ }^{[35,36]}$. Gupta investigated the residence time distribution ${ }^{[37]}$, asymmetry and oscillation of the fluid flow pattern ${ }^{[38,39]}$, and slag entrainment ${ }^{[40,41]}$. Tanaka et al ${ }^{[42]}$ and Wang et al ${ }^{[44]}$ studied the influence of wettability on the behavior of argon bubbles and fluid flow. Teshima et al ${ }^{[19]}$ and Iguchi et al ${ }^{[43]}$ studied slag entrainment. However, there are few papers with measurements of level fluctuations at the

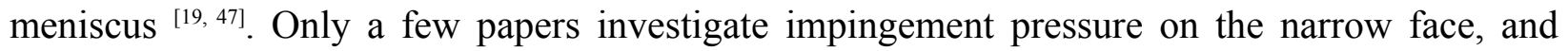
believe that lower pressure is better. ${ }^{[48,49]}$

In the current work, the Weber-Froude similarity criterion was used to design the water model for the gas-water two phase fluid flow phenomena of interest. For the high-velocity flow conditions present in a steel continuous caster, fully-developed turbulent flow conditions are 
always produced, so achieving Reynold's similarity by matching the ratio of the momentum and diffusion forces was judged to be less important, so long as fully-turbulent flow conditions are maintained.

First, invoking Froude similarity to ensure equal ratios of the momentum and buoyancy forces in the water model (w) and steel caster (s) gives:

$$
F r=\left(\frac{U^{2}}{g L}\right)_{\mathrm{w}}=\left(\frac{U^{2}}{g L}\right)_{\mathrm{s}}
$$

where $\mathrm{Fr}$ is the Froude number, $U$ is a characteristic velocity $(\mathrm{m} / \mathrm{s}), g$ is the gravitational acceleration rate $\left(\mathrm{m} / \mathrm{s}^{2}\right), L$ is a characteristic length $(\mathrm{m})$. Substituting the geometry scale factor, $\lambda=\mathrm{L}_{\mathrm{w}} / \mathrm{L}_{\mathrm{s}}$, into Eq.(1) gives:

$$
\frac{U_{w}}{U_{s}}=\sqrt{\lambda}
$$

Second, applying Weber similarity to match the ratio of the momentum and surface tension forces implies

$$
W e=\left(\frac{\rho U^{2} L}{\sigma}\right)_{\mathrm{w}}=\left(\frac{\rho U^{2} L}{\sigma}\right)_{\mathrm{s}},
$$

where We is the Weber number, $\rho$ is the liquid density, $7020 \mathrm{~kg} / \mathrm{m}^{3}$ for molten steel and 998 $\mathrm{kg} / \mathrm{m}^{3}$ for water, and $\sigma$ is the surface tension, 1.6 for molten steel and $0.073 \mathrm{~N} / \mathrm{m}$ for water.

Combining Eqs. (2) \& (3) gives:

$$
\lambda=\left(\frac{\rho_{S}}{\rho_{w}} \frac{\sigma_{w}}{\sigma_{S}}\right)^{1 / 2} \sim 0.6
$$

Thus, a 0.6-scale water model can satisfy both Froude similarity and Weber similarity simultaneously. An additional requirement is to scale down the water flow rate $\left(Q_{w}\right)$ relative to the molten steel throughput ( $\left.Q_{S}\right)\left(\mathrm{m}^{3} /\right.$ hour) according to:

$$
\frac{Q_{w}}{Q_{s}}=\frac{U_{w} L_{w}^{2}}{U_{s} L_{s}^{2}}=\lambda^{2.5}=0.279
$$


The casting speed (measured for the solid strand) is related to the liquid steel flow rate from the following mass balance, which considers the effect of steel solidification on the density.

$$
V_{C}=\frac{Q_{S}}{S}\left(\frac{1 h r}{60 \min }\right)\left(\frac{7800}{7020}\right)
$$

where $V_{C}$ is the steel casting speed ( $\left.\mathrm{m} / \mathrm{min}\right), Q_{S}$ is the liquid steel flow rate $\left(\mathrm{m}^{3} / \mathrm{hr}\right), S$ is the crosssection area of the strand $\left(\mathrm{m}^{2}\right)$, and $7800 / 7020$ is the ratio of solid to liquid steel densities. Combining Eq.(5) and (6) gives the relationship between casting speed in the real caster and flow rate in the water model (Table I). For a $200 \mathrm{~mm} \times 900 \mathrm{~mm}$ strand,

$$
\mathrm{V}_{\mathrm{C}}(\mathrm{m} / \mathrm{min})=0.298 \mathrm{Q}_{\mathrm{w}}\left(\mathrm{m}^{3} / \mathrm{hr}\right)
$$

and for a $200 \mathrm{~mm} \times 1250 \mathrm{~mm}$ strand,

$$
\mathrm{V}_{\mathrm{C}}=0.214 \mathrm{Q}_{\mathrm{w}}
$$

A suggested argon flow rate to use in the steel continuous casting is found by matching the modified Froude numbers in the water model and steel caster,

$$
F r^{\prime}=\frac{\rho_{N_{2}} V_{N_{2}}^{2}}{\left(\rho_{w}-\rho_{N_{2}}\right) \cdot g \cdot L_{w}}=\frac{\rho_{A r} V_{A r}^{2}}{\left(\rho_{S}-\rho_{A r}\right) \cdot g \cdot L_{S}}
$$

where Fr' is the modified Froude number, $\rho_{g}$ and $\rho_{l}$ are the density of the gas and liquid $\left(\mathrm{kg} / \mathrm{m}^{3}\right)$, and $\mathrm{V}_{\mathrm{g}}$ is the gas velocity $(\mathrm{m} / \mathrm{s})$. Here $\rho_{\mathrm{w}}=998 \mathrm{~kg} / \mathrm{m}^{3}, \rho_{\mathrm{s}}=7020 \mathrm{~kg} / \mathrm{m}^{3}, \rho_{A r}=1.783 \mathrm{~kg} / \mathrm{m}^{3}$, $\rho_{\mathrm{N} 2}=1.251 \mathrm{~kg} / \mathrm{m}^{3}$. The gas flow rate is $\mathrm{Q}_{\mathrm{g}}=\mathrm{V}_{\mathrm{g}} \cdot 1 / 4 \pi \mathrm{D}_{\mathrm{n}}{ }^{2}$, where $\mathrm{D}_{\mathrm{n}}$ is the diameter of the hole in the bottom of the stopper rod through which the gas enters the SEN. In the water model, $\mathrm{D}_{\mathrm{n}, \mathrm{w}}=0.004 \mathrm{~m}$, and in the steel caster $\mathrm{D}_{\mathrm{n}, \mathrm{s}}=0.005 \mathrm{~m}$.

Evaluating Eq.(9) at standard pressure (1 atm) and $1550^{\circ} \mathrm{C}$ gives

$$
\mathrm{Q}_{\mathrm{Ar}}=2.885 \mathrm{Q}_{\mathrm{N} 2}
$$

Considering the six-fold increase in volume during heating of the injected gas to steel temperature, the argon gas flow at the standard temperature $\left(0^{\circ} \mathrm{C}\right)$ should be

$$
\mathrm{Q}_{\mathrm{Ar}}=0.420 \mathrm{Q}_{\mathrm{N} 2}
$$


It should be mentioned that although the Froude, Weber, and modified-Froude similarity criteria are all simultaneously satisfied, the similarity between the water model and steel caster needs further investigation. Recent work has found that the multiphase fluid flow pattern in a 0.4-scale water model based on Froude similarity did not match the fluid flow pattern in the molten steel caster, although a numerical simulation was found to match both. ${ }^{[50,51]}$

\section{B. Orthogonal Design of Water Model Experiments}

A schematic of the water model is shown in Figure 2. A straight-mold steel caster of a $200 \mathrm{~mm}$ thick and $1250 \mathrm{~mm}$ wide strand is modeled with a water model that is $1200 \mathrm{~mm}$ in length, $120 \mathrm{~mm}$ in thickness, and varies in width from $774.6 \mathrm{~mm}$ at the top to $753.3 \mathrm{~mm}$ at the bottom. A second strand width of $900 \mathrm{~mm}$ is modeled with a top width of $557.7 \mathrm{~mm}$, and bottom width of $542.4 \mathrm{~mm}$. The example SEN configuration is also shown in Fig. 2. The $\mathrm{N}_{2}$ gas, used to model the argon gas in the molten steel, is injected into the mold through a central circular hole (4mm in diameter) in the bottom of the stopper rod.

Firstly the flow rate and water heights in the tundish and mold are maintained steady for 5 minutes by adjusting the position of the stopper rod and the outlet flow valve. The water height in the tundish is $600 \mathrm{~mm}$ if not specified otherwise. Then the level fluctuation, impingement pressure, and location of the lower roll center are each measured three times, and the means are recorded. The definition of the level fluctuation is the mean of the 5 largest level fluctuations during each 40 s measurement. This is because large level fluctuations account more for the slag entrainment than small ones. The impingement pressure is the mean of the measured pressure for 40s measured near the impingement point of the narrow face, subtracting the static water pressure $\left(\rho_{\mathrm{w}} \mathrm{gh}\right)$. The location of the center of the lower roll is measured from the top surface.

All initial flow pattern studies were conducted with the recessed nozzle. The effects of six factors of casting speed, SEN submergence depth (the distance from the meniscus to the top of SEN outports), gas flow rate, SEN outport angle, inner diameter of SEN, the area ratio $\psi$ (the total area of the two outports to the SEN bore cross-section area), and the bottom well shape on the level fluctuation, impingement pressure and location of the lower roll center are investigated. For each factor, there are five values to be investigated, as shown in Table II. Each single water model experiment combines one set values of factors. In general, if there are $k$ factors with $n$ 
values, the total number of combinations is $n^{k}$. For the current study, the total number of combinations is $5^{6}=15625$. When the number of factors and the number of values are small, it may be feasible to test all the combinations. Very often, it is not possible or cost effective to test all the combinations. It is desirable to sample a small but representative sample of combinations for testing. The Orthogonal Experimental Design (OED) was developed for this purpose. ${ }^{[2-57]}$. It provides a series of orthogonal arrays for different number of factors and different number of values. $L_{m}\left(n^{k}\right)$ denotes an orthogonal array for $k$ factors and $n$ values, where $L$ denotes a Latin square and $m$ is the number of combinations to be tested. An example of $L_{9}\left(3^{4}\right)$ is shown in Table III. In this table, each row represents a combination of factor values. The orthogonality of an array means that 1) for the factor in any column, every value occurs the same number of times; 2) for the two factors in any two columns, every combination of two values occurs the same number of times; and 3) the selected combinations are uniformly distributed over the whole space of all the possible combinations. It has been proved that the orthogonal design is optimal to use a far reduced number of selected combinations to well represent for all the possible combinations. ${ }^{[52,57]}$ The OED method has been used for the water model experiments of the fluid flow in continuous casting mold. ${ }^{[58,59]}$ For the current studies, measurements in the water model with recess-bottom SEN were performed for 25 different sets of conditions for each of the two size water models according to the three rules of OED, and examples are given in Table IV.

\section{Computational Models}

Since simulations of fluid flow and heat transfer in a cylindrical continuous casting mold with a straight nozzle were published in 1970 by Szekely et al ${ }^{[60]}$, many investigations on fluid flow in continuous casting mold have been conducted using mathematical models. ${ }^{[61-79]}$. These fluid flow models have produced insights into the flow pattern in the nozzle ${ }^{[46,67,80-82]}$ and mold ${ }^{[25,34,83-87]}$, including the effects of nozzle geometry ${ }^{[36,44,46,67,88]}$, argon gas injection ${ }^{[18,80-82]}$, impingement of the superheated steel jet onto the solidifying shell at the narrow face ${ }^{[89]}$, shape and fluctuations of the top surface level ${ }^{[77,90-92]}$, electromagnetic forces, ${ }^{[75,93]}$, and inclusion entrapment ${ }^{[78]}$.

In the current paper, three-dimensional fluid flow in the water model of the tundish, the SEN and the mold are calculated with k- $\varepsilon$ turbulence model, using a single-phase Eulerian model of the liquid phase in Fluent ${ }^{[94]}$. The trajectories of many individual bubbles are predicted by considering the buoyancy and drag forces acting on the bubbles using an uncoupled Lagrangian 
model, which includes the effect of turbulent flow fluctuations with a Random-Walk model ${ }^{[61,79]}$. This approach is only reasonable for very small gas fractions, such as found when the only source of gas is argon leaking through the slide gate seals inside the SEN. Detailed equations can be found elsewhere. ${ }^{[79,86]}$ For the simulation of fluid flow, a fixed velocity condition is imposed at the domain inlet, and a "pressure outlet condition" is used at the outlets. For simplicity, the top surface is assumed to be flat with no slag phase, and zero shear stress. Standard "wall functions" with zero velocity at the wall are used as boundary conditions in order to capture the steep gradients with reasonable accuracy on a coarse grid. ${ }^{[66-68]}$ The bubbles are assumed to escape at the top surface and the mold bottom, and to be reflected at other walls.

\section{Plant Experiments}

Industrial trials and measurements in the actual steel plant are crucial to ultimately quantify the effects of casting variables on quality concerns, owing to the great complexity of the phenomena. High casting speed variations were observed to increase mold slag entrainment. ${ }^{[95]}$ To decrease these problems, the top surface velocity should be kept below a critical maximum velocity, which has been estimated to be $0.3 \mathrm{~m} / \mathrm{s}^{[48]}$ or $0.4 \mathrm{~m} / \mathrm{s}^{[24]}$. However, some minimal surface flow, including level fluctuations at the meniscus, is required in order to prevent quality problems such as meniscus freezing, ${ }^{[96]}{ }^{[24]}$ capturing of inclusions into the meniscus surface and deep oscillation marks. For example, decreasing surface velocity below $0.4 \mathrm{~m} / \mathrm{s}$ was measured to increase surface pinhole defects. ${ }^{[97]}$ To avoid these problems, the flow pattern should be designed to exceed a critical minimum velocity across the top surface, estimated to be about $0.1-0.2 \mathrm{~m} / \mathrm{s}^{[24]}$ Although the detrimental effect of level fluctuations is well known, only a few industrial measurements have quantified the effects. ${ }^{[19,77]}$ Level fluctuations of $6-9 \mathrm{~mm}$ at the meniscus during continuous-casting was reported to cause the fewest surface defects in cold-rolled coils. ${ }^{[19]}$ This corresponds to optimal level fluctuations in the water model of this work of $3.6-5.4 \mathrm{~mm}$ using Eq. (4). The waves and level fluctuations on the top surface in a water model were smaller than those in the steel caster, as predicted by Yuan, and confirmed by comparison with measurements. ${ }^{[7]}$ Fluid flow velocities in the steel caster were measured using electromagnetic sensors ${ }^{[98-100]}$ and validated using water and computational models ${ }^{[86]}$ These experiments revealed the-single roll or double roll- nature of the flow pattern in the real steel casting mold. 
In the current study, industrial trials are performed for a 3-heat sequence (240 tonne total) cast with a slab size of $200 \mathrm{~mm} \times 1250 \mathrm{~mm}$, casting speed of $1.0-1.2 \mathrm{~m} / \mathrm{min}$. The purposes of the industrial trials are to check the effect of the optimized SEN configuration in water model, and the optimal operation conditions, such as the suitable argon gas injection. In the trials to investigate inclusions in steel, there is no gas injection. To trace the origin of inclusions caused by mold slag entrainment, $\mathrm{La}_{2} \mathrm{O}_{3}$ is added to the mold flux before casting. The caster has two strands: strand 1 is with the recess well SEN, and strand 2 is with pointed-bottom SEN.

Molten steel samples are taken from the continuous casting mold at the $1 / 4$ width and $100 \mathrm{~mm}$ below the surface of the molten steel to analyze the Total Oxygen (T.O.) and the nitrogen. Great care was taken during sample collection to avoid contamination with liquid slag or air. This was accomplished using a sample collecting ladle with a closing lid. This sample ladle was inserted into the molten steel quickly and taken out after several seconds. The steel sample was then machined off the surface at the work shop, and polished for later microscope observation and T.O. and $\mathrm{N}$ analysis.

Slab samples were sectioned and analyzed with an optical microscope to reveal and count typical inclusions. The schematic of sampling of slab is shown in Figure 3. The complete size distribution including the rare large inclusions $(>50 \mu \mathrm{m})$ was determined with Slime tests ${ }^{[101]}$, which involved dissolving the steel away from the inclusions in $2 \mathrm{~kg}$ steel samples taken from solid slabs.

Liquid mold slag samples were taken to study the change in $\mathrm{Al}_{2} \mathrm{O}_{3}$ content during continuous casting. The thickness of the liquid slag is measured at $10 \mathrm{~mm}$ from the narrow face, at the $1 / 4$ width centerline, and $10 \mathrm{~mm}$ from the SEN, by vertically inserting steel spikes into the molten steel and slag layer for several seconds.

\section{FLOW IN THE NOZZLE}

Three kinds of fluid flow pattern were observed in the SEN water model, as shown in Figure 4: bubbly flow (Fig.4a), annular flow (Fig.4b) and critical flow between these two (Fig.4c). For the "bubbly flow" pattern, the water and the gas are well mixed, and the jets at the two outports are relatively uniform and symmetrical. Turbulence in the SEN is very strong, so both the liquid and gas phases have large energy losses, leading to a small jet energy and low impingement pressure at the narrow face. In addition, the strong interaction between the gas and the liquid in the SEN 
likely tends to dislodge any inclusions just attached to the SEN walls, which lowers the tendency for clogging.

For the "annular flow" pattern, the liquid annularly enters the SEN and then flows down along the walls, as it periodically changes its position. The liquid flow separates from the gas, which forms large pockets just below the stopper. The energy loss is small, so the impingement pressure to the narrow face is high. The flow is unstable, so the jets from the two outports tend to be asymmetrical. A given outport may emit more gas and less water, as the large gas regions escape and move intermittently along the outer walls of SEN to the top surface, where they rupture. This creates large level fluctuations and might contribute to the foam observed near the SEN. ${ }^{[30]}$ At the other outport, there would be more water and less gas, giving the jet high momentum and speed, leading to high impingement pressure on the narrow face, and large meniscus level fluctuations.

For the critical flow pattern, part of the inside of the SEN is bubbly flow, and the rest is annular flow. A tiny change of the water height in the tundish, casting speed, or gas flow rate can switch this critical flow to annular flow or to bubbly flow. If the flow regime suddenly switches to annular flow, the resistance to flow increases, which causes the water height in the tundish to increase abruptly, and the level in the mold to decrease abruptly. Water may even overflow the tundish. If the flow regime suddenly switches to bubbly flow, the resistance to flow decreases, which causes the water height in the tundish to decrease abruptly, and the level in the mold to increase abruptly. Water may even overflow the mold. Clearly, this flow pattern is detrimental to steel quality. These findings agree closely with the observations in the SEN of annular and bubbly flow by Burty ${ }^{[102-104]}$.

This behavior is characteristic of nozzles with oversized ports, relative to the nozzle bore, which are chosen to provide tolerance to clogging. However, these ports produce very small pressure drops and provide minimal resistance to flow transients. They exhibit low velocity regions of back flow at the top of the ports (see Figure 5b), which is consistent with previous predictions for this port-to-bore ratio ${ }^{[68,105]}$. These regions are very susceptible to the intermittent gas bubble release that accompanies annular flow and causes asymmetric flow in the mold. The flow pattern in the SEN with a fixed-bore diameter is controlled by the liquid and gas flow rates, and the pressure (which depends on tundish level). The bubbly flow pattern in the SEN is most likely at 
low gas flow rate and high liquid flow. As the casting speed is increased, the range of the gas flow rate required to maintain bubbly flow is also increased, in other words, with increasing casting speed more gas can be injected into the liquid with achieving the bubbly flow pattern in the nozzle. For a given casting speed, there is a maximum gas flow rate to achieve bubbly flow. Beyond this maximum gas flow rate, the flow pattern in the nozzle will be annular flow, as shown in Figure 6. For example, if the water throughput is $6 \mathrm{~m}^{3} /$ hour, and the liquid height in the tundish is $600 \mathrm{~mm}$, the gas flow rate should be smaller than $19.5 \mathrm{Nl} / \mathrm{min}$ for bubbly flow. Increasing liquid height in the tundish allows a slightly greater gas flow rate to retain bubbly flow, with other conditions kept constant.

In the real steel caster, a bubbly flow pattern in the SEN is desired to prevent unstable and asymmetrical flow in the mold. The results in Fig. 6 can be converted into the steel-argon system and related to casting speed by applying the similarity criterion, Eq. (5), and the mass balance equation, Eq. (6). Using Eqs.(7), (8) and (11), Fig.6 was redrawn into Figure 7 to suggest corresponding relations in the steel continuous casting process. It must be re-emphasized that these predicted flow regimes need validation with better computational models and plant experiments.

\section{FLOW IN THE MOLD}

Two distinct types of flow pattern in the mold are single roll and double roll. Table III summarizes the single or double roll flow patterns obtained in the water model resulting from different conditions. This work confirms previous findings that the single roll flow pattern is more likely with high gas injection, small SEN submergence depth and small casting speed ${ }^{[18,106]}$. The double roll flow pattern is more likely with large casting speed, large SEN submergence depth, and small gas flow rate ${ }^{[18,106]}$.

With minimal argon gas injection, and oversized, downward-directed ports, the fluid flow pattern in the mold region of the Panzhihua caster is a typical "double-roll flow pattern. This is shown in the typical single-phase simulation results in Fig.5, which includes computations of fluid flow in the tundish, SEN and mold regions. The jet impinges on the narrow face, where part of the flow moves upwards along the narrow face to form the upper roll, and another part flows downwards to generate the lower roll (Fig.5c \& d). The fluid flow is slightly asymmetrical, which is likely a convergence problem induced by the unstructured mesh used at the region of 
the SEN outports. Although this is a numerical problem, the actual flow pattern exhibited similar asymmetries, which are consistent with those observed elsewhere ${ }^{[76]}$. The calculated location of the upper roll is $0.13 \mathrm{~m}$ below the top surface, and the lower roll is $0.57-0.72 \mathrm{~m}$ below the top surface. In the water model measurements for these conditions with no gas, the left low roll is located $0.61 \mathrm{~mm}$ below the top surface, roughly matching the simulation.

\section{A. Effect of gas flow rate and casting speed}

The water model results in Figure 8 show that increasing casting speed with other variables held constant encourages the double-roll flow pattern. The flow patterns in Figure 9 show the same trend, with the complication that increasing gas flow rate was compensated by increasing submergence depth. In the single roll flow pattern (a), the top surface level near the SEN is highest, whereas with the strong double-roll flow pattern (b), the level near the narrow face is highest. Note that for the low casting speed, bubbles leave the jet and move up along the outer SEN walls, according to their buoyancy. With excessive gas flow rates, this may emulsify the slag at the top surface near the SEN. The single-roll flow pattern also tends to increase top surface level fluctuations.

Excessive argon injection may generate transient variations of the jets entering the mold, introduce asymmetry in the mold cavity, ${ }^{[107]}$ and increase surface turbulence. To maintain a stable double-roll flow pattern, which is often optimal ${ }^{[98,100]}$, the argon gas flow rate should be kept safely below a critical level. ${ }^{[98,99,108]}$ The critical level depends on the casting speed, submergence depth, nozzle angle and other flow parameters, which is consistent with previous work, discussed in detail elsewhere. ${ }^{[18,80-82]}$

\section{B. Lower-Roll Location}

Figure 10 shows the effects of process parameters on the depth of the center of the lower recirculation roll. This point becomes deeper with increasing casting speed and decreasing gas flow rate. These trends are the same as those favoring the double-roll flow pattern. In addition, the lower roll center becomes deeper with increasing submergence depth, or decreasing SEN bore diameter.

\section{TOP SURFACE MOLD LEVEL FLUCTUATIONS}

Level fluctuations cause surface defects in addition to slag entrainment at the meniscus. Level fluctuations are mainly induced by jet impingement and upwards flow along the narrow face, 
rupture of bubbles at the top of the liquid, a single roll flow pattern in the mold, the gas injection, and the transient, asymmetric nature of turbulent flow itself. A typical trace of the level fluctuation recorded at $1 / 4$ point on the top surface of the water model is given in Figure 11, and divided into low and high frequency components by averaging the fluctuation with some time step and subtracting the fluctuation with averaged value. The averaged value is the low frequency oscillation, as shown in Fig. 11 (b), which stems from the asymmetrical flow ${ }^{[28,109]}$. The high frequency fluctuation (Fig.11c) is mainly generated by the chaotic nature of the turbulence ${ }^{[68]}$. The amplitude of the low and high frequency components is similar, around $+/-$ $5 \mathrm{~mm}$. However, the longer duration of the low frequency oscillation likely make this component worse for causing quality problems.

The effects of different process conditions on the average maximum level fluctuation at different locations across the top surface centerline of the water model are shown in Figs. 12-17. These figures include variations owing to changes in other variables besides those indicated. All of the results indicate that the level fluctuations at the meniscus near the narrow face are smaller than those in the interior (centerline) at the quarter-width locations or near the SEN. They also indicate that level fluctuations for the $900 \mathrm{~mm}$ width are larger than for the $1250 \mathrm{~mm}$ width.

\section{A. $\quad$ Effect of Gas Flow Rate and Casting Speed}

Level fluctuations at the meniscus increase with increasing gas flow rate, as the flow pattern tends to single roll (Figure 12). When the casting speed is low, or the gas flow rate is high, the gas mainly exits the top surface near the SEN, (Fig.8a), so level fluctuations are worse near the SEN. With high casting speed, the bubbles follow the jet further and tend to exit closer to the narrow face, where the largest level fluctuations are then found. For the same conditions, the smaller width slab has larger level fluctuations. This might be because the turbulent energy is more easily dissipated in the larger volume. For the same conditions, the meniscus region generally has smaller level fluctuations than the interior of the top surface. To obtain 3.6-5.4mm level fluctuations at the narrow face meniscus, the gas flow rate for the $1250 \mathrm{~mm}$ width slab should be within 5.3.-6.9 Nl/min, and for the $900 \mathrm{~mm}$ width slab, the gas flow rate should be within 4.6-7.6 N1/min.

Past work has found that larger casting speed tends to induce larger level fluctuations at the meniscus ${ }^{[100]}$. In this work, however, casting speed has no clear effect on the level fluctuations 
(Figure 13), due to compensating changes in the flow pattern. Increasing speed tends to switch from a single to a double roll flow pattern, which decreases surface velocities. This tends to offset the general increase in surface velocity caused by the higher speed. Moreover, flow stability and transient oscillations, which are most responsible for level fluctuations, is not directly related to speed when gas is present.

\section{B. Effect of Submergence Depth}

Level fluctuations at the meniscus decrease with increasing submergence depth to about $70 \mathrm{~mm}$ (Figure 14). Further increasing the submergence depth beyond $100 \mathrm{~mm}$ switches to increasing the level fluctuations. The reason for this small effect is change from single to double-roll flow pattern with increasing submergence depth. The best submergence depth is around 70-100mm, which produces $5.1 \mathrm{~mm}$ level fluctuation at the meniscus for the $1250 \mathrm{~mm}$ width, and $5.7 \mathrm{~mm}$ for the $900 \mathrm{~mm}$ width.

\section{Effect of Nozzle Geometry}

Figure 15 shows that the SEN outport angle should be downwards $5-15^{\circ}$ because level fluctuations increase for angles outside of this range. Increasing angle tends to generate the single roll flow pattern, which has larger level fluctuations. Too large a downward angle may enhance flow pattern asymmetry, with corresponding large level fluctuations.

As shown in Figure 16, the level fluctuations decrease with increasing bore diameter of the SEN. This is likely due to decreasing the size of the channel between the SEN outer bore and the mold walls, which lowers surface velocity there. This prevents communication between the two sides of the mold, which tends to discourage flow asymmetry and the associated level fluctuations. The larger bore diameter of SEN also affects the fluid flow pattern in the SEN. With a larger bore, the fluid flow velocity in the nozzle is smaller. Thus the jet into the mold has the smaller energy, decreasing the level fluctuations.

The optimal inner diameter of the SEN is $45 \mathrm{~mm}$, and the optimal ports-to-bore ratio is 2.27 for both the $900 \mathrm{~mm}$ and $1250 \mathrm{~mm}$ widths (outer diameter $=65 \mathrm{~mm}$, keeping thickness $10 \mathrm{~mm}$ ). With this bore size, the level fluctuations at the meniscus are $7.27 \mathrm{~mm}$ for the $900 \mathrm{~mm}$ width, and $5.32 \mathrm{~mm}$ for the $1250 \mathrm{~mm}$ width. 
Figure 17 shows that level fluctuations decrease slightly with increasing the ports-to-bore area ratio $\psi$. This might be due to lowering the exit velocity. However, if the area ratio is too big, it likely causes more asymmetrical flow.

\section{NARROW FACE IMPINGEMENT PRESSURE}

Figure 18 shows the effects of some parameters on jet impingement pressure to the narrow face. For the $900 \mathrm{~mm}$ width, the impingement pressure increases with increasing casting speed and decreasing inner diameter of the SEN. The impingement pressure is smallest for the $900 \mathrm{~mm}$ width if the gas flow rate is $9.2 \mathrm{Nl} / \mathrm{min}$, the outport angle is downwards $15^{\circ}$, and the submergence depth is $100 \mathrm{~mm}$. If the area ratio is smaller than 1.75 , the impingement pressure decreases with increasing area ratio. For the same conditions, the impingement pressure for the $1250 \mathrm{~mm}$ width is smaller than for the $900 \mathrm{~mm}$ width. For the $1250 \mathrm{~mm}$ width, the impingement pressure is independent of the submergence depth and the bore diameter of the SEN.

\section{IMPROVED RECESS-BOTTOM SEN DESIGN}

Careful study of the fluid flow results reveals that no nozzle design is best for all casting conditions, or for all attributes of the flow pattern. Never-the-less, an improved nozzle design was chosen and casting conditions were restricted according to slab width. The common compromised recess-bottom SEN configuration chosen for the water model was: $45 \mathrm{~mm}$ inner bore diameter, downwards $15^{\circ}, 90 \mathrm{~mm}$ submergence depth, and 2.27 area ratio. For the real steel caster, this corresponds to a $75 \mathrm{~mm}$-diameter inner bore, with $150 \mathrm{~mm}$ submergence depth.

For the continuous casting of $200 \mathrm{~mm} \times 900 \mathrm{~mm}$ slabs, casting speed is restricted to $1.4-1.5 \mathrm{~m} / \mathrm{min}$. The best gas flow rate for these conditions is $4.58 \mathrm{Nl} / \mathrm{min}$ in the water model, or $1.92 \mathrm{Nl} / \mathrm{min}$ in the steel caster. For the $200 \mathrm{~mm} \times 1250 \mathrm{~mm}$ slabs, casting speed is restricted to $1.2-1.3 \mathrm{~m} / \mathrm{min}$. The best range of gas flow rates is 5.34-6.87 N1/min for the water model, or 2.24-2.90 N1/min for the steel caster. From Fig.6, these casting speeds and gas flow rates should generate bubbly flow in the SEN.

\section{EFFECT OF SEN BOTTOM WELL ON FLUID FLOW IN THE MOLD}

Before this project, the current steel plant uses the traditional pointed-bottom-well SEN during continuous casting pouring. Water model experiments with the $200 \mathrm{~mm} \times 1250 \mathrm{~mm}$ mold were 
performed with this pointed-bottom SEN and the optimized recess-bottom SEN configuration with $4.6 \mathrm{Nl} / \mathrm{min}$ gas flow rate and $90 \mathrm{~mm}$ submergence depth. The measured level fluctuation, the impingement depth and the location of the lower roll center are shown in Figure 19. For the pointed bottom SEN, the level fluctuations are generally smaller, which may not provide enough heat transfer to the meniscus. However, it has larger level fluctuations near the SEN at low and high casting speeds, owing to being prone to flow asymmetry. Finally, the pointed bottom SEN has larger impingement pressure, and greater impingement depth, which is not good for inclusion removal in the mold. Although this study is somewhat inconclusive, the recess-well SEN appears to be superior.

\section{GAS BUBBLE ENTRAPMENT}

At optimal levels, bubbles injected into the nozzle are helpful by reducing nozzle clogging, lifting the fluid flow pattern to encourage inclusion removal, decreasing the impingement pressure at the narrow face, and capturing inclusions as they flow in the liquid ${ }^{[30,110-112]}$. However, if the casting speed is too large or the gas flow rate is too high, some bubbles, especially those with many entrapped solid oxide particles, may be captured by the solidifying shell, eventually leading to surface slivers or internal defects. ${ }^{[30]}$ Bubbles may also be entrapped at the meniscus, especially if large oscillation hooks or large level fluctuations occur.

The calculated trajectories of 10 typical bubbles with $1 \mathrm{~mm}(\mathrm{a}, \mathrm{b})$ and $5 \mathrm{~mm}(\mathrm{c}, \mathrm{d})$ diameter in the single phase water mold of Fig.5 are shown in Figure 20. Very rarely, a large bubble may penetrate deep and be entrapped through the bottom outlet. More of the $1 \mathrm{~mm}$ bubbles leave the outlet at the mold bottom. The bubble motion in the mold is very chaotic, varying from symmetrical to asymmetrical, which corresponds with transient biased flow in the mold.

\section{INDUSTRIAL MEASUREMENT OF INCLUSION ENTRAPMENT}

Plant trials were to estimate the fluid flow pattern in the mold, and to compare the steel cleanliness of cast slabs poured using the optimized recess-well SEN by water models with that using traditional pointed-bottom SEN, and also were performed to observe and quantify the amount of inclusions captured in the solid steel strand, compared to those removed safely into the top slag layer. At the two-strand caster in the current study, strand 1 uses the recess-well nozzle, and strand 2 uses the traditional pointed-bottom nozzle. 


\section{A. $\quad$ Fluid Flow Pattern in the Mold with Gas Injection}

According to Fig.7, for the casting of $200 \mathrm{~mm} \times 1250 \mathrm{~mm}$ steel slabs at $1.1 \mathrm{~m} / \mathrm{min}$ casting speed with $1000 \mathrm{~mm}$ steel height in the tundish, the argon gas flow rate should be below $6.5 \mathrm{Nl} / \mathrm{min}$ to get the bubbly flow pattern in the SEN. However, in the previous continuous casting operations with pointed-bottom SEN, the gas flow rate used prior to this study was $10-20 \mathrm{Nl} / \mathrm{min}$, which is predicted in Fig. 7 to produce annular flow in the SEN, inducing biased flow in the mold, serious level fluctuations and slag entrainment. Indeed, chaotic fluctuations, somewhat periodically, were observed beneath the surface of the slag layers in the steel caster, especially at the $1 / 4$ width of the mold. Somewhat periodically, "jumping" of the flux, or burning of mold flux (as shown in Figure $21^{[113]}$ ), even accompanied by opening of an "eye", or bare spot on the top surface of the molten steel with no slag cover, could be observed. This detrimental flow state is termed "jumping of the fish", and is induced by the transient and asymmetry flow pattern in the whole mold. After changing to a new recess-bottom SEN configuration optimized by water model and lowering the gas flow rate to the bubbly flow regime below the line in Fig. 7, this phenomenon was diminished. During times such as ladle changes, when the tundish height and casting speed decrease, the gas flow rate must drop greatly to satisfy this criterion and maintain bubbly flow in the SEN.

Asymmetrical variations in the transient flow structure in the mold are important because they may be linked with observations of inclusion entrapment from side to side ${ }^{[12,114]}$, also may induce the serious top slag fluctuation, and the "jumping of fish" flow, as discussed in III and Fig.21. The associated asymmetrical surface velocities induce vortices at the top surface. In the water model, the vortex location was observed to move periodically with time. This asymmetrical flow could be induced by both 1) operational and 2) natural causes:

1) Operation Conditions

- Off-center stopper rod, and off center gas injection from the stopper rod;

- Off-center positioning of the SEN in the mold;

- Uneven bottom shape of the SEN due to manufacturing, erosion or clogging problems;

- Asymmetrical shape of the two ports including the port diameter and port angle;

- Asymmetrical gas injection through the slide gate, or porous brick of the SEN;

- Changes in casting speed or gas flow rate, such as during ladle changes;

2) Natural causes of fluid flow asymmetry in the SEN and mold 
- Asymmetrical clogging of the nozzle causing asymmetric flow

- Asymmetrical inflow due to flow across the bottom well of the tundish;

- Chaotic nature of turbulence of the fluid flow in the mold ${ }^{[38,115]}$;

- Transient flow oscillations induced by the gas injection, such as annular flow (Fig. 4);

The natural causes are suspected to be more important. To minimize the detrimental asymmetries caused by flow transients, it is important to address the above problems, in addition to designing the flow system to be resistant to asymmetries. It is also important to maintain a constant liquid steel level in the mold, constant powder feeding rate, constant casting speed, constant gas injection fraction, ${ }^{[81]}$ constant slide gate opening, and fixed nozzle position (alignment and submergence). The transient flow and asymmetrical fluid flow in the mold need to be further investigated in detail in the future.

\section{B. Inclusion Observation}

Figure 22 shows typical large inclusions in the slab, extracted from the residue of the slimes tests, of samples taken from the ladle change casting period. Many of the particles contain $\mathrm{La}_{2} \mathrm{O}_{3}$ tracer (Table IV), indicating mold slag. Most of these slag inclusions are also spherical, which indicates that they were liquid when captured by the steel. This demonstrates that mold slag entrainment is a serious problem during continuous casting. This confirms the importance of the efforts here to improve steel cleanliness, which focus on optimizing the mold flow pattern to decrease mold slag entrainment.

Microscope observations at $\sim 300$ separate fields ( $0.3 \mathrm{~mm}$ diameter each field), per sample were used to quantify the ratio of inclusion area to steel area in five samples, taken during steady casting. The results, given in Table V, show that Strand 2 (pointed-bottom SEN) had $\sim 13 \%$ more inclusions (lower cleanliness) than Strand 1 (recessed nozzle).

\section{Liquid Slag Layer Analysis}

The measured thickness of the liquid flux layer is shown in Table VI. The liquid flux at the narrow-face meniscus is $1-3 \mathrm{~mm}$ thicker than that at $1 / 4$ width and near the SEN. The recess-well SEN generates $3 \mathrm{~mm}$ more liquid flux thickness than the pointed-bottom SEN. POSCO reported that for low carbon Al-killed steel, if the casting speed is $1.0-1.6 \mathrm{~m} / \mathrm{min}$, the best thickness of the liquid slag layer should be $10-15 \mathrm{~mm} .{ }^{[116]}$ In the current investigation, Strand 2 (pointed-bottom SEN) had insufficient slag layer thickness. This could disrupt meniscus solidification, leading to 
deep hooks, which can capture bubbles and inclusions. This might explain the lower cleanliness observed for the pointed-bottom SEN.

The absorption of alumina inclusions from the molten steel into the liquid flux on top of the mold has two components: 1) increasing the $\mathrm{Al}_{2} \mathrm{O}_{3}$ content from the mold powder composition $\left(2.84 \% \mathrm{Al}_{2} \mathrm{O}_{3}\right)$ to the measured alumina concentration at steady state and 2) maintaining that value as flux is consumed.

The mass of the liquid slag layer, $W_{\mathrm{LS}}$ (in $\mathrm{kg}$ ), can be calculated by,

$$
W_{L S}=S \cdot h \cdot \rho_{\text {slag }}
$$

where $S$ is the cross section area of the strand $\left(0.2 \times 1.25 \mathrm{~m}^{2}\right), h$ is the thickness of the liquid slab layer ( $\mathrm{m}$, in Table VI), and $\rho_{\text {slag }}$ is the density of the slag, $3500 \mathrm{~kg} / \mathrm{m}^{3}$.

$\mathrm{Al}_{2} \mathrm{O}_{3}$ inclusions removed to the liquid layer of the top slag at the mold can be calculated by, $W_{\mathrm{Al} 2 \mathrm{O} 3}($ in $\mathrm{kg})$

$$
W_{\mathrm{Al}_{2} \mathrm{O}_{3}}=\frac{W_{L S} \cdot \Delta \mathrm{Al}_{2} \mathrm{O}_{3}}{100}
$$

where $\Delta \mathrm{Al}_{2} \mathrm{O}_{3}$ is the increment of $\mathrm{Al}_{2} \mathrm{O}_{3}$ in the slag in \% (Table VII).

$\mathrm{Al}_{2} \mathrm{O}_{3}$ inclusions removed to all the slag, $M_{\mathrm{Al} 2 \mathrm{O} 3}$ (in $\mathrm{kg}$ ), can be estimated by

$$
M_{\mathrm{Al}_{2} \mathrm{O}_{3}}=\frac{M_{\text {slag }} \cdot W_{\text {steel }} \cdot \Delta \mathrm{Al}_{2} \mathrm{O}_{3}}{100}
$$

where $M_{\text {slag }}$ is mold flux consumption, $0.5 \mathrm{~kg} /$ tonne steel here, and $W_{\text {Steel }}$ is the total molten steel poured per strand, 120 tonne here.

The total oxygen removed at the mold, $\Delta \mathrm{O}(\mathrm{ppm})$, can be represented by

$$
\Delta O=\frac{\left(W_{\mathrm{Al}_{2} \mathrm{O}_{3}}+M_{\mathrm{Al}_{2} \mathrm{O}_{3}}\right) \times \frac{48}{102}}{W_{\text {steel }} \times 1000} \times 10^{6}
$$

Based on the measured liquid flux thickness (Table VI), the mass of the liquid slag layer is $11.20 \mathrm{~kg}$ (strand 1) and $9.01 \mathrm{~kg}$ (strand 2) calculated by Eq.(12). This corresponds to $0.492 \mathrm{~kg}$ of $\mathrm{Al}_{2} \mathrm{O}_{3}$ from the steel (strand 1) and $0.473 \mathrm{~kg}$ (strand 2) calculated by Eq.(13). Next, based on the 
mold flux consumption rate of $0.5 \mathrm{~kg} /$ tonne, and total of 120 tonnes of steel cast per strand during the sequence, the total liquid slag consumed from the top surface is $60 \mathrm{~kg}$ per strand. By Eq.(14), $\mathrm{Al}_{2} \mathrm{O}_{3}$ inclusions removed to all the slag is of $2.634 \mathrm{~kg}$ (strand 1), and $3.150 \mathrm{~kg}$ (strand 2). Dividing the total increase $(3.126 \mathrm{~kg}$ strand 1 and $3.623 \mathrm{~kg}$ strand 2$)$ over the entire heat (120 tonnes per strand) and Converting from alumina (102g/mol) to oxygen ( $48 \mathrm{~g} / \mathrm{mol})$ with Eq.(15) gives 12.3ppm total oxygen removed from the steel (strand 1) and 14.2ppm (strand 2). The results are given in Table VIII.

\section{Total Oxygen and Slime Test Analysis of Steel Slabs}

The mean of the total oxygen of the molten steel in the mold of Strand 1 is around 59 $\pm 35 \mathrm{ppm}$ (Figure 23). It is assumed that the total oxygen in the tundish entering both strands has similar total oxygen values. Then, inclusion removal is $20.8 \%$ from strand 1 , and $24.1 \%$ from strand 2 , based on the estimation of T.O. removed to the top slag. This inclusion removal fraction by the mold slag agrees with the measured and simulated fractions of inclusions removed in the mold of a different $250 \mathrm{~mm} \times 1300 \mathrm{~mm}$ caster using a different measurement method. ${ }^{[114]}$ Moreover, in strand 1, the total oxygen based on this inclusion mass balance is estimated to be $(59 \pm 35) \times(100 \%-20.8 \%)=46.7 \pm 28 \mathrm{ppm}$, which matches well with the simple total-oxygen measurement of $47 \pm 20 \mathrm{ppm}$ in a slab from this strand. The greater inclusion removal fraction from strand 2 might be due to statistical variations, or it might indicate that mold slag entrainment is an important source of inclusions (not accounted for in this rough calculation) that is a more serious problem for the pointed bottom nozzle.

The steel cleanliness is complicated greatly by the variations that occur during startup, ladle change periods, and end of casting. This is investigated for the two SEN bottom shapes by measuring the total oxygen and nitrogen in the molten steel in the mold as a function of casting time and the amount of large inclusions in the slab extracted by the Slime method. The results, given in Fig. 23, show that there is an abrupt increase in inclusions at the time of each ladle change. This might be aggravated by reoxidation from air absorption, slag entrainment in the tundish (due to emulsification during ladle opening or due to the lower tundish level), asymmetrical fluid flow from annular flow in the SEN induced by the low casting speed and other reasons. Furthermore, the start and end of casting have almost ten-fold more inclusions than during steady casting. This is when the above air absorption and slag entrainment 
phenomena are the most extreme. The period of the ladle change (3.3-4.3mg inclusions $10 \mathrm{~kg}$ steel) has twice the cleanliness problem of steady state pouring (1.6-2.2 mg inclusions per $10 \mathrm{~kg}$ steel). Solving the cleanliness problems that occur during process transients is clearly an important task.

\section{CONCLUSIONS}

In the current paper, multiphase fluid flow and particle motion in the SEN and the mold of the slab continuous caster at Panzhihua Steel is investigated using water models, numerical simulations and industrial measurements. In a 0.6 -scale water model, designed according to the Weber-Froude similarity criterion, the top surface level fluctuations, the jet impingement pressure, and the flow pattern in the SEN and the mold are measured. The effects of SEN geometry, submergence depth, mold width, casting speed, and gas flow rate are investigated. Three kinds of fluid flow pattern are observed in the SEN: bubbly flow, annular flow, and an intermediate critical flow structure. The annular flow structure induces detrimental asymmetrical flow in the mold. Moreover, its higher resistance to flow makes switching between flow structures prone to level fluctuations, which is even more detrimental. The SEN flow structure depends on the liquid flow rate, the gas flow rate, and the liquid height in the tundish. The gas flow rate should be adjusted with changes in the casting speed in order to maintain stable bubbly flow.

Two main flow patterns are observed in the mold: single roll and double roll. The single roll flow pattern is generated by large gas injection, small SEN submergence depth and low casting speed. To maintain a stable double-roll flow pattern, which is often optimal, the argon should be kept safely below a critical level. The chosen optimal nozzle had $45 \mathrm{~mm}$ inner bore diameter, downwards $15^{\circ}$ port angle, 2.27 port-to-bore area ratio, and a recessed-bottom. The pointed bottom SEN generates smaller level fluctuations at the meniscus, larger impingement pressure, deeper impingement, and more inclusion entrapment in the strand than the recess-bottom SEN.

Numerical simulation shows that on occasion, even large bubbles can penetrate deeply and be entrapped through the bottom outlet. This is more likely for $1 \mathrm{~mm}$ bubbles than for $5 \mathrm{~mm}$ bubbles. Due to the turbulent fluctuations, the motion of the bubbles in the mold is very random and sometimes asymmetrical. Mass balances of inclusions from slag and slab measurements shows 
that around $20 \%$ of the alumina inclusions are removed from the steel into the mold slag. However, entrainment of the mold slag itself is a critical problem. Inclusions in the steel increase two-fold during ladle changes,. Slabs cast during the start and end of a sequence have the most inclusions.

\section{ACKNOWLEDGMENTS}

The authors wish to thank the many steel workers at Panzhihua Steel and students at the University of Science and Technology Beijing who participated in this project, and for support from the Continuous Casting Consortium at the University of Illinois. 


\section{References}

1. H.T. Tsai, W.J. Sammon and D.E. Hazelton: "Characterization and Countermeasures for Sliver Defects in Cold Rolled Products", in Steelmaking Conf. Proc., vol. 73, Iron and Steel Society, Warrendale, PA, 1990, pp. 49-59.

2. S. Chakraborty and W. Hill: "Reduction of Aluminum Slivers at Great Lakes No.2 CC", 77th Steelmaking Conf. Proc., ISS, Warrendale, PA, 1994, vol. 77, pp. 389-95.

3. H. Uehara, H. Osanai, J. Hasunuma, K. Hara, T. Nakagawa, M. Yoshida and S. Yuhara: "Continuous Casting Technology of Hot Cycle Operations of Tundish for Clean Steel Slabs", La Revue de Metallurgie - CIT, 1998, vol. 95 (10), pp. 1273-85.

4. M. Byrne, T.W. Fenicle and A.W. Cramb: "The Sources of Exogenous Inclusions in Continuous Cast, Aluminum-Killed Steels", Steelmaking Conference Proceedings, 1985, vol. 68, pp. 451-61, 999.

5. M. Byrne, T.W. Fenicle and A.W. Cramb: "The Sources of Exogenous Inclusions in Continuous Cast, Aluminum-Killed Steels", I \& Smaker, 1988, vol. 15 (6), pp. 41-50, 999.

6. M. Byrne, T.W. Fenicle and A.W. Cramb: "The Sources of Exogenous Inclusions in Continuous Cast, Aluminum-Killed Steels", ISS Trans., 1989, vol. 10, pp. 51-60, 999.

7. P. Rocabois, J.-N. Pontoire, V. Delville and I. Marolleau: "Different Slivers Type Observed in Solla Steel Plants and Improved Practice to Reduce Surface Defects on Cold Roll Sheet", in ISSTech2003 Conference Proceedings, ISS, Warrandale, PA, 2003, pp. 995-1006.

8. A. Jungreithmeier, E. Pissenberger, K. Burgstaller and J. Mortl: "Production of ULC IF Steel Grades at Voestalpine Stahl GmbH, Linz", in ISSTech2003 Conference Proceedings, vol. Electric Furnace and Steelmaking, ISS, Warrandale, PA, 2003, pp. 227-40.

9. A.R. Obman, W.T. Germanoski and R.C. Sussman: "Surface and Subsurface Defects on Stainless Steel First Slabs", in 64th Steelmaking Conference Proc, vol. 64, ISS, Warrendale, PA, 1981, pp. 254-58.

10. J. Yoshida, M. Iguchi and S. Yokoya: "Water Model Experiment on Mold Powder Entrapment around the Exit of Immersion Nozzle in Continuous Casting Mold", Tetsu-toHagane, 2001, vol. 87 (8), pp. 529-35.

11. N.A. McPherson: "Continuous Cast Clean Steel", in Steelmaking Conference Proceedings, vol. 68, ISS, Warrendale, PA, 1985, pp. 13-25. 
12. H. Jacobi, H.-J. Ehrenberg and K. Wunnenberg: "Developement of the Cleanness of Different Steels for Flat and Round Products", Stahl und Eisen, 1998, vol. 118 (11), pp. 87-94.

13. T. Wei and F. Oeters: "A Model Test for Emulsion in Gas-Stirred Ladles", Steel Research, 1992, vol. 63 (2), pp. 60-68.

14. M. Iguchi, Y. Sumida, R. Okada and Z. Morita: "Evaluation of the Critical Gas Flow Rate Using Water Model for the Entrapment of Slag Into a Metal Bath Subject to Gas Injection", Tetsu-to-Hagane, 1993, vol. 79 (5), pp. 569-75.

15. S.-H. Kim and R.J. Fruehan: "Physical Modeling of Liquid/Liquid Mass Transfer in Gas Stirred Ladles", Metall. Trans. B, 1987, vol. 18B (2), pp. 381-90.

16. I. Manabu, S. Yutaka, O. Ryusuke and M. Zen-Ichiro: "Eveluation of the Critical Gas Flow Rate Using Water Model for the Entrpment of Slag into a Metal Bath Subject to Gas Injection", Tetsu-to-Hagane, 1993, vol. 79 (5), p. 33.

17. R. McDavid and B.G. Thomas: "Flow and Thermal Behavior of the Top-Surface Flux/ Powder Layers in Continuous Casting Molds", Metall. Trans. B, 1996, vol. 27B (4), pp. 672-85.

18. B.G. Thomas, X. Huang and R.C. Sussman: "Simulation of Argon Gas Flow Effects in a Continuous Slab Caster", Metall. Trans. B, 1994, vol. 25B (4), pp. 527-47.

19. T. Teshima, J. Kubota, M. Suzuki, K. Ozawa, T. Masaoka and S. Miyahara: "Influence of Casting Conditions on Molten Steel Flow in Continuous Casting Mold at High Speed Casting of Slabs", Tetsu-to-Hagane, 1993, vol. 79 (5), pp. 576-82.

20. J. Kubota, K. Okimoto, A. Shirayama and H. Murakami: "Meniscus Flow Control in the Mold by Travelling Magnetic Field for High Speed Slab Caster", in Proceedings, 6th International Iron and Steel Congress, vol. 3, Iron \& Steel Inst. Japan, Tokyo, 1990, pp. 356-63.

21. J. Kubota, K. Okimoto, M. Suzuki, A. Shirayama and T. Masaoka: "Mechanism of Level Fluctuation and Mold Powder Catching in Slab Continuous Casting at High Speeds", ISC. The Sixth International Iron and Steel Congress. Vol. 3. Steelmaking I, (Nagoya, Japan, 21-26 Oct. 1990), 1990, pp. 356-63.

22. Y. Sasabe, S. Kubota, A. Koyama and H. Miki: "Real-time Expert System Applied to Mold Bath Level Control of Continuous Caster", ISIJ Int., 1990, vol. 30 (2), pp. 136-41.

23. J. Kubota, K. Okimoto, A. Shirayama and H. Murakami: "Meniscus Flow Control in the Mold by Travelling Magnetic Field for High Speed Slab Caster", in Mold Operation for Quality and Productivity, A.W. Cramb and E. Szekeres, eds., Iron and Steel Society, 1991 , 
24. J. Kubota, K. Okimoto, A. Shirayama and H. Murakami: "Meniscus Flow Control in the Mold by Travelling Magnetic Field for High Speed Slab Caster", in Steelmaking Conference Proceedings, vol. 74, Iron and Steel Society, Warrendale, PA, 1991, pp. 233 41.

25. B.G. Thomas: "Chapter 14. Fluid Flow in the Mold", in Making, Shaping and Treating of Steel: Continuous Casting, vol. 5, A. Cramb, ed., AISE Steel Foundation, Pittsburgh, PA, 2003, pp. 14.1-14.41.

26. W.H. Emling, T.A. Waugaman, S.L. Feldbauer and A.W. Cramb: "Subsurface Mold Slag Entrainment in Ultra Low Carbon Steels", 77th Steelmaking Conference Proceedings, ISS, Warrendale, PA, 1994, vol. 77, pp. 371-79.

27. S. Feldbauer and A. Cramb: "Insights into Slag Entrainment in the Mold of a Continuous Caster", in PTD Conference Proceedings, vol. 13, ISS, Warrendale, PA, 1995, pp. 327-40.

28. T. Honeyands and J. Herbertson: "Flow Dynamics in Thin Slab Caster Moulds", Steel Research, 1995, vol. 66 (7), pp. 287-93.

29. M. Gebhard, Q.L. He and J. Herbertson: "Vortexing Phenomena in Continuous Slab Casting Moulds", in Steelmaking Conference Proceedings, vol. 76, Iron and Steel Society, 1993, pp. 441-46.

30. W.H. Emling, T.A. Waugaman, S.L. Feldbauer and A.W. Cramb: "Subsurface Mold Slag Entrainment in Ultra-Low Carbon Steels", in Steelmaking Conference Proceedings, vol. 77, (Chicago, IL, April 13-16, 1997), ISS, Warrendale, PA, 1994, pp. 371-79.

31. K.I. Afanaseva and T.P. Iventsov: Stal, 1958, vol. 18 (7), p. 599.

32. N.T. Mills and L.F. Barnhardt: "Development of submerged entry tundish nozzles", J. of Metals, 1971, vol. 23 (11), pp. 37-43.

33. N.T. Mills and L.F. Barnhardt: "The development of submerged entry tundish nozzles for strand casting steel slabs", Open Hearth Proceedings, TMS-AIME, 1971, vol. 54, pp. 303-15.

34. J. Szekely and R.T. Yadoya: "The Physical and Mathematical Modeling of the Flow Fiel in Mold Region in Continuous Casting System: Part I. Model Studies with Aqueous Systems", Metall. Trans. B, 1972, vol. 3 (5), pp. 2673-80.

35. L.J. Heaslip and J. Schade: "Physical Modeling and Visualization of Liquid Steel Flow Behavior During Continuous Casting", Iron Steelmaker, 1999, vol. 26 (1), pp. 33-41.

36. L.J. Heaslip, I.D. Sommerville, A. McLean, L. Swartz and W.G. Wilson: "Model Study of Fluid Flow and Pressure Distribution During SEN Injection - Potential for Reactive 
Metal Additions During Continuous Casting", Iron Steelmaker, 1987, vol. 14 (8), pp. 4964.

37. D. Gupta, S. Subramaniam and A.K. Lahiri: "Study of Fluid Flow and Residence-Time Distribution in a Continuous Slab Casting Mould", Steel Res., 1991, vol. 62 (11), pp. 496500 .

38. D. Gupta, S. Chakraborty and A.K. Lahiri: "Asymmetry and Oscillation of the Fluid Flow Pattern in a Continuous Casting Mould: a Water Model Study", ISIJ Int., 1997, vol. 37 (7), pp. 654-58.

39. D. Gupta and A.K. Lahiri: "A Water Model Study of the Flow Asymmetry Inside a Continuous Slab Casting Mold", Metallurgical and Materials Transactions B, 1996, vol. 27B (5), pp. 757-64.

40. D. Gupta and A.K. Lahiri: "Cold model study of the surface profile in a continuous slab casting mold: effect of second phase", Metallurgical and Materials Transactions B, 1994, vol. 27B (4), pp. 695-98.

41. D. Gupta and A.K. Lahiri: "Cold Model Study of Slag Entrainment into Liquid Steel in a Continuous Slab Caster", Ironmaking Steelmaking, 1996, vol. 23 (4), pp. 361-63.

42. H. Tanaka, H. Kuwatori and R. Nisihara: "Analysis of Continuous Casting Powder Entrapping Phenomena by Water-model Experiment", Tetsu-to-Hagane, 1992, vol. 78 (5), pp. 761-66.

43. M. Iguchi, J. Yoshida, T. Shimzu and Y. Mizuno: "Model Study on the Entrapment of Mold Powder into Molten Steel", ISIJ Int., 2000, vol. 40 (7), pp. 685-91.

44. Z. Wang, K. Mukai and D. Izu: "Influence of Wettability on the Behavior of Argon Bubbles and Fluid Flow insie the Nozzle and Mold", ISIJ Int., 1999, vol. 39 (2), pp. 15463.

45. M. Iguchi and N. Kasai: "Water Model Study of Horizontal Molten Steel-Ar Two-Phase Jet in a Continuously Casting Mold", Metallurgical and Materials Transactions B, 2000, vol. 31B (3), pp. 453-60.

46. B.G. Thomas, L.J. Mika and F.M. Najjar: "Simulation of Fluid Flow Inside a Continuous Slab Casting Machine", Metall. Trans. B, 1990, vol. 21B (2), pp. 387-400.

47. X. Huang and B.G. Thomas: "Modeling of Transient Flow Phenomena in Continuous Casting of Steel", Canadian Metall. Quart., 1998, vol. 37 (304), pp. 197-212.

48. J. Herbertson, Q.L. He, P.J. Flint and R.B. Mahapatra: "Modelling of Metal Delivery to Continuous Casting Moulds", in Steelmaking Conf. Proceedings, vol. 74, ISS, Warrendale, PA, 1991, pp. 171-85. 
49. J. Herbertson and P. Austin: "The Application of Mathematical Models for Optimization of Continuous Casting", Modelling of Casting, Welding, and Advanced Solidification Processes - VI, T.S. Piwonka, V. Voller and L. Katgerman, eds., (Palm Coast, FL), TMS, Warrendale, PA, 1993, vol. VI, pp. 689-700.

50. L. Zhang and B.G. Thomas: Effect of Argon Gas Distribution on FLuid Flow in the Mold Using Time-Averaged $k-\varepsilon$ Models, University of Illinois at Urbana-Champaign, Report No. CCC200402, 2004.

51. Q. Yuan, T. Shi, B.G. Thomas and S.P. Vanka: "Simulation of Fluid Flow in the Continuous Casting of Steel", Computational Modeling of Materials, Minerals and Metals Processing, TMS, B. Cross, Evans, ed., (Seattle, WA, Feb. 18-20,2002), TMS (The Materials, Minerals, and Metals Society), Warrendale, PA, 2001, pp. 491-500.

52. Q. Wu: "On the Optimality of Orthogonal Experimental Design", Acta Mathematicae Applacatae Sinica, 1978, vol. 1 (4), pp. 283-99.

53. D.C. Montgomery: Design and Analysis of Experiments, 3rd ed., Wiley, New York, 1991.

54. K.T. Fang and Y. Wang: Numer-Theoretic Methods in Statistics, Chapman \& Hall, New York, 1994.

55. Q. Zhang and Y.-W. Leung: "An Orthogonal Genetic Alglorithm for Multimedia Multicast Routing", IEEE Transactions on Evolutionary Computation, 1999, vol. 3 (1), pp. 53-62.

56. Y.-W. Leung and Y. Wang: "An Orthogonal Genetic Alglorithm with Quantization for Global Numerical Optimization", IEEE Transactions on Evolutionary Computation, 2001, vol. 5 (1), pp. 41-53.

57. W.S. Yang, F. Jona and O.M. Marcus: "Application of Orthogonal Experimental Design to LEED Crystallography", J. Vac. Sci. Technol. B, 1983, vol. 1 (3), pp. 718-22.

58. Y. Bao, J. Zhu, N. Tian and B. Xu: "Experimental Study of Fluid Flow in Thin Slab Continuous caster Mould with Water-Model", Journal of University of Science and Technology Beijing(English Edition), 1999, vol. 6 (1), pp. 15-19.

59. R. Sanchez-Perez, R.D. Morales, M. Diaz-Cruz, O. Olivares-Xometl and J. PalafoxRamos: "A Physical Model for the Two-Phase Flow in a Continuous Casting Mold", ISIJ Inter., 2003, vol. 43 (5), pp. 637-46.

60. J. Szekely and V. Stanek: "On Heat Transfer and Liquid Mixing in Continuous Casting of Steel", Metallurgical and Materials Transactions, 1970, vol. 1 (1), p. 119. 
61. B.G. Thomas and L. Zhang: "Mathematical Modeling of Fluid Flow in Continuous Casting", ISIJ Inter., 2001, vol. 41 (10), pp. 1181-93.

62. S.K. Choudhary and D. Mazumdar: "Mathematical Modelling of Transport Phenomena in Continuous Casting of Steel", ISIJ Int., 1994, vol. 34 (7), pp. 584-92.

63. S.K. Choudhary and D. Mazumdar: "Mathematical Modelling of Fluid Flow, Heat Transfer and Solidification Phenomena in Continuous Casting of Steel", Steel Res., 1995, vol. 66 (5), pp. 199-205.

64. J. Szekely and R.T. Yadoya: "The Physical and Mathematical Modelling of the Flow Field in the Mold Region of Continuous Casitng Systems. Part II. The Mathematical Representation of the Turbulence Flow Field", Metall. mater. trans., 1973, vol. 4 (5), pp. 1379-88.

65. S. Asai and J. Szekely: "Turbeulent Flow and its Effects in Continuous Casting", Ironmaking Steelmaking, 1975, vol. 3 (3), p. 205.

66. B.E. Launder and D.B. Spalding: "Numerical Computation of Turbulent Flows", Comp. Meth. Applied Mechanics and Engr., 1974, vol. 13 (3), pp. 269-89.

67. B.G. Thomas and F.M. Najjar: "Finite-Element Modeling of Turbulent Fluid Flow and Heat Transfer in Continuous Casting", Applied Mathematical Modeling, 1991, vol. 15 (5), pp. 226-43.

68. D.E. Hershey, B.G. Thomas and F.M. Najjar: "Turbulent Flow through Bifurcated Nozzles", Int. J. Num. Meth. in Fluids, 1993, vol. 17 (1), pp. 23-47.

69. M. Yao, M. Ichimiya, M. Tamiya, K. Suzuki, K. Sugiyama and R. Mesaki: "Three Dimensional Analysis of Molten Metal Flow in Continuous Casting Mould", Trans. Iron Steel Inst. Japan, 1984, vol. 24 (2), p. s211.

70. M. Yao, M. Ichimiya, S. Kiyohara, K. Suzuki, K. Sugiyama and R. Mesaki: "Three Dimensional Analysis of Molten Steel Flow in Continuous Casting Mould", 68th Steelmaking Conference Proceedings, AIME, ISS, 1985, pp. 27-33.

71. J. Smagorinsky: "General Circulation Experiments With the Primitive Equations, I. The Basic Experiment", Monthly Weather Review, 1963, vol. 91, pp. 99-164.

72. S. Sivaramakrishnan, B.G. Thomas and S.P. Vanka: "Large Eddy Simulation of Turbulent Flow in Continuous Casting of Steel", in Materials Processing in the Computer Age, vol. 3, V. Voller and H. Henein, eds., TMS, Warrendale, PA, 2000, pp. 189-98. 
73. Y. Tanizawa, M. Toyoda, K. Takatani and T. Hamana: "Behavior of Second Phase Particles in Continuous Casting Process", La Revue de Metallurgie - CIT, 1993, vol. 90 (8), pp. 993-1000.

74. I. Sawada, Y. Kishida, K. Okazawa and H. Tanaka: "Numerical Analysis of Molten Steel Flow in Continuous Casting Mold by Use of Large Eddy Simulation", Tetsu-to-Hagane, 1993, vol. 79 (2), pp. 160-36.

75. I. Sawada, K. Okazawa, E. Takeuchi, K. Shigematsu and H. Tanaka: "Development and Application of Simulator for Analyzing Molten Steel Flow and Inclusion Behavior in Continuous Casters", Nippon Steel Technical Report, 1995, (67), pp. 7-12.

76. Q. Yuan, S. Sivaramakrishnan, S.P. Vanka and B.G. Thomas: "Computational and Experimental Study of Turbulent Flow in a 0.4-Scale Water Model of a Continuous Steel Caster", Metall. \& Mater. Trans., 2004, vol. 35B (5), pp. 967-82.

77. Q. Yuan, B.G. Thomas and S.P. Vanka: "Study of Transient Flow and Particle Transport during Continuous Casting of Steel Slabs, Part 1. Fluid Flow", Metal. \& Material Trans. B., 2004, vol. 35B (4), pp. 685-702.

78. Q. Yuan, B.G. Thomas and S.P. Vanka: "Study of Transient Flow and Particle Transport during Continuous Casting of Steel Slabs, Part 2. Particle Transport." Metal. \& Material Trans. B., 2004, vol. 35B (4), pp. 703-14.

79. L. Zhang, J. Aoki and B.G. Thomas: "Inclusion Removal by Bubble Flotation in Continuous Casting", in Materials Science \& Technology 2004 (MS\&T'04), vol. 2, TMS \& AIST, Warrandale, PA, 2004, pp. 161-78.

80. H. Bai and B.G. Thomas: "Turbulent Flow of Liquid Steel and Argon Bubbles in SlideGate Tundish Nozzles, Part I, Model Development and Validation", Metallurgical and Materials Transactions B, 2001, vol. 32B (2), pp. 253-67.

81. H. Bai and B.G. Thomas: "Turbulent Flow of Liquid Steel and Argon Bubbles in SlideGate Tundish Nozzles, Part II, Effect of Operation Conditions and Nozzle Design", Metallurgical and Materials Transactions B, 2001, vol. 32B (2), pp. 269-84.

82. H. Bai and B.G. Thomas: "Effects of Clogging, Argon Injection and Continuous Casting Conditions on Flow and Air Aspiration in Submerged Entry Nozzles", Metallurgical and Materials Transactions B, 2001, vol. 32B (4), pp. 702-22.

83. A. Imamura, A. Kusano and N. Moritama: "A Hydrodynamical Analysis of the Molten Steel Flow in the Continuous Casting Mold", Tetsu-to-Hagane, 1992, vol. 78 (3), p. $101 \sim 06$. 
84. N. Bessho, R. Yoda and H. Yamasaki: "Numerical Analysis of Fluid Flow in Continuous Casting Mold by Bubble Dispersion Model", in Procedings of 6th Int. Iron and Steel Congress, vol. 3, ISIJ, Tokyo, Japan, 1990, pp. 340-47.

85. B. Grimm, P. Andrzejewski, K. Wagner and K.-H. Tacke: "Flow and Separation of Inclusions in CC Slab / Ingot Molds", Stahl und Eisen, 1995, vol. 115 (2), pp. 71-78.

86. B.G. Thomas, Q. Yuan, S. Sivaramakrishnan, T. Shi, S.P. Vanka and M.B. Assar: "Comparison of Four Methods to Evaluate Fluid Velocities in a Continuous Casting Mold", ISIJ Int., 2001, vol. 41 (10), pp. 1262-72.

87. L. Zhang, S. Yang, X. Wang, K. Cai, J. Li, X. Wan and B.G. Thomas: "Physical, Numerical and Industrial Investigation of Fluid Flow and Steel Cleanliness in the Continuous Casting Mold at Panzhihua Steel", in AISTech2004, ISS, Warrandale, PA, 2004, pp. 879-94.

88. F.G. Wilson, M.J. Heesom, A. Nicholson and A.W.D. Hills: "Effect of fluid flow characteristics on nozzle blockage in aluminium-killed steels", Ironmaking Steelmaking, 1987, vol. 14 (6), pp. 296-309.

89. X. Huang, B.G. Thomas and F.M. Najjar: "Modeling Superheat Removal during Continuous Casting of Steel Slabs", Metall. Trans. B, 1992, vol. 23B (6), pp. 339-56.

90. J. Anagnostopoulos and G. Bergeles: "Three-Dimensional Modeling of the Flow and the Interface Surface in a Continuous Casting Mold Model", Metallurgical and Materials Transactions B, 1999, vol. 30B (6), pp. 1095-105.

91. A. Theodorakakos and G. Bergeles: "Numerical Investigation of the Interface in a Continuous Steel Casting Mold Water Model", Metallurgical and Materials Transactions B, 1998, vol. 29B (6), pp. 1321-27.

92. G.A. Panaras, A. Theodorakakos and G. Bergeles: "Numerical Investigation of the Free Surface in a continuous Steel Casting Mold Model", Metallurgical and Materials Transactions B, 1998, vol. 29B (5), pp. 1117-26.

93. R.H.M.G. Nabben, R.P.J. Duursma, A.A. Kamperman and J.L. Lagerberg: "Modelling of Electromagnetic Broake and Its Influence on Bubble Entrapment", Ironmaking Steelmaking, 1998, vol. 25 (5), pp. 403-06.

94. FLUENT6.1-Mannual: Fluent Inc., Lebanon, New Hampshire, Report, 2003.

95. G. Shi, L. Zhang, Y. Zheng, J. Zhi, W. Wang, J. Zhang, W. Wang and X. Wang: "Investigation on Non-metallic Inclusions in LCAK Steel Produced by BOF-CAS-CC Production Route", Iron \& Steel (in Chinese), 2000, vol. 35 (3), pp. 12-15. 
96. J. Birat, M. Larrecq, J. Lamant and J. Petegnief: "The Continuous Casting Mold: A Basic Tool for Surface Quality and Strand Produtivity", in Mold Operation for Quality and Productivity, A.W. Cramb and E. Szekeres, eds., Iron and Steel Society, Warrendale, PA, 1991, pp. 3-14.

97. M. Hanao, M. Kawamoto, H. Mizukami and K. Hanazaki: "Influence of Velocity of Molten Steel Flow near the Meniscus in a Continuous Casting Mold on Surface Quality of Slabs", in Steelmaking Conference Proceedings, vol. 82, ISS, Warrendale, PA, 1999, pp. 63-70.

98. P.H. Dauby, M.B. Assar and G.D. Lawson: "PIV amd MFC Measurements in a Continuous Caster Mould. New Tools to Penetrate the Caster Black Box", La Revue de Metallurgie - CIT, 2001, vol. 98 (4), pp. 353-66.

99. M.B. Assar, P.H. Dauby and G.D. Lawson: "Opening the Black Box: PIV and MFC Measurements in a Continuous Caster Mold", in Steelmaking Conference Proceedings, vol. 83, ISS, Warrendale, PA, 2000, pp. 397-411.

100. P.H. Dauby and S. Kunstreich: "Electromagnetic Stirring in Slab Caster Molds What and Why", in ISSTech2003, ISS, Warrandale, PA, 2003, pp. 491-503.

101. L. Zhang and B.G. Thomas: "State of the Art in Evaluation and Control of Steel Cleanliness", ISIJ Inter., 2003, vol. 43 (3), pp. 271-91.

102. M. Burty, C. Pusse, M. Alvarez and P. Gauje: "Fundamental Study of Gas-Liquid Flows in CC Machine", 2001 Steelmaking Conference (ISS), B.M. A., ed., (Baltimore, U.S.A.), Kanagy D. L., 2001, vol. 84, pp. 89-98.

103. M. Burty, M. Larrecq, C. Pusse and Y. Zbaczyniak: "Experimental and Theoretical Analysis of Gas and Metal Flows in Submerged Entry Nozzles in Continuous Casting", in PTD Conference Proceedings, vol. 13, (La Revue de Metallurgie-CIT, October, 1996, pp. 1249-1255.), ISS, Warrendale, PA, 1995, pp. 287-92.

104. U. Sj 鰏 tr 鰉, M. Burty, A. Gaggioli and J. Radot: "An Experimental Study of Argon Injection and Aspiration of Air into Stopper Rod in Continuous Casters", in 81st Steelmaking Conference Proceedings, vol. 81, (Toronto, Canada, March 22-25, 1998), ISS, Warrendale, PA, 1998, pp. 63-71.

105. F.M. Najjar, B.G. Thomas and D.E. Hershey: "Turbulent Flow Simulations in Bifurcated Nozzles: Effects of Design and Casting Operation", Metall. Trans. B, 1995, vol. 26B (4), pp. 749-65.

106. D. Creech: Computational Modeling of Multiphase Turbulent Fluid Flow and Heat Transfer in the Continuous Slab Casting Mold, M.S. Thesis, University of Illinois at Urbana-Champaign, 1998. 
107. Z. Wang, K. Mukai, Z. Ma, M. Nishi, H. Tsukamoto and F. Shi: "Influence of Injected Ar Gas on the Involvement of the Mold Powder under Different Wettabilities between Porous Refractory and Molten Steel", ISIJ Int., 1999, vol. 39 (8), pp. 795-803.

108. T. Shi and B.G. Thomas: Effect of Gas Bubble Size on Fluid Flow in Continuous Casting Mold, Continuous Casting Consortium at University of Illinois at Urbana-Champaign, Report, 2001.

109. T. Honeyands, J. Lucas, J. Cambers and J. Herbertson: "Preliminary Modelling of Steel Delivery to Thin Slab Caster Moulds", in Steelmaking Conference Proceedings, vol. 75, ISS, Warrendale, PA, 1992, pp. 451-59.

110. G. Abbel, W. Damen, G. decendt and W. Tiekink: "Argon Bubbles in Slabs", ISIJ, 1996, vol. 36, pp. S219-S22.

111. L. Kiriha, H. Tosawa and K. Sorimachi: "Behavior of Alumina CLuster in Ultra Low Carbon Steel during Steelmaking Process", VCAMP-ISIJ, 2000, vol. 13, p. 120.

112. L. Zhang and S. Taniguchi: "Fundamentals of Inclusions Removal from Liquid Steel by Bubbles Flotation", International Materials Reviews, 2000, vol. 45 (2), pp. 59-82.

113. J. Wei, Z. Tian, L. Zhang, K. Cai and Y. Zhou: "Inclusions in the Low Carbon Al-killed Steel Produced by a CSP Thin Slab Casting Process at Handan Steel", in Proccedings of AISTech 2005 Iron \& Steel Technology Conference and Exposition, Vol.II, AIST, Warrandale, PA, 2005, pp. 585-92.

114. L. Zhang, B.G. Thomas, K. Cai, L. Zhu and J. Cui: "Inclusion Investigation during Clean Steel Production at Baosteel", in ISSTech2003, ISS, Warrandale, PA, 2003, pp. 141-56.

115. Q. Yuan, B.G. Thomas and S.P. Vanka: "Turbulent Flow and Particle Motion in Continuous Casting Mold." in ISSTech2003 Conference Proceedings, ISS, Warrandale, PA, 2003, pp. 913-27.

116. I.R. Lee, J. Chai and K. Shin: "Optimization Technology of Mold Powder According to Casting Conditions", in 71th Steelmaking Conference Proc, vol. 71, ISS, Warrendale, PA, 1988 


\section{Captions:}

Table I Relationship between the flow rate and the casting speed

Table II Parameters used in the water model

Table III Orthogonal array $L_{9}\left(3^{4}\right)$ : nine combinations for four factors with three values.

Table IV Fluid flow pattern in the water model the mold

Table V Composition of typical large inclusions in the slab from mold slag entrainment

Table VI Area percentage (\%) of inclusions by microscope observation

Table VII Measured thickness of liquid slag layer on the top of the mold (mm)

Table VIII Measured $\mathrm{Al}_{2} \mathrm{O}_{3}$ fraction in the liquid flux of the mold and estimated total oxygen removal in the steel by SEN and the mold (initial $\mathrm{Al}_{2} \mathrm{O}_{3}$ content in the flux: $2.84 \%$ )

Fig.1 Mechanisms of slag entrainment in the continuous casting mold ${ }^{[10]}$

Fig.2 Schematic of the water model experiment (1: $\mathrm{N}_{2}$ tank, 2: pressure measurement probe, 3 : tundish, 4: level fluctuation measurement probes, 5: water flow meter, 6: Data collection system, 7: Computer, 8: pump, 9: mold, 10: water collection tank, 11: gas flow meter, 12: dimension of the SEN outports)

Fig.3 Sampling places at continuous casting slab

Fig.4 The multiphase fluid flow pattern in the SEN with $45 \mathrm{~mm}$ bore diameter

Fig.5 Calculated single phase fluid flow in the tundish, the SEN and the mold (water model of the $200 \mathrm{~mm} \times 1250$ mold, casting speed: $1.4 \mathrm{~m} / \mathrm{min}$, tundish inlet velocity: $0.731 \mathrm{~m} / \mathrm{s}$, inlet turbulent energy: $0.004 \mathrm{~m}^{2} / \mathrm{s}^{2}$, and its dissipation rate: $0.03 \mathrm{~m}^{2} / \mathrm{s}^{3}$, SEN bore diameter: $45 \mathrm{~mm}$, outport angle: down $15^{\circ}$, Submergence depth of the SEN: $130 \mathrm{~mm}$, water height in the tundish: $600 \mathrm{~mm}$, tundish length: $1400 \mathrm{~mm}$, tundish thickness: $400 \mathrm{~mm}$ )

Fig.6 The conditions to achieve annular flow or the bubbly flow in a $45 \mathrm{~mm}$ SEN (water model)

Fig.7 The conditions to change annular flow to bubbly flow in a $75 \mathrm{~mm}$ SEN (liquid steel) for different size slabs

Fig.8 Two phase fluid flow pattern in the water model of the $200 \mathrm{~mm} \times 1250 \mathrm{~mm}$ steel slab (bore diameter of the SEN: $45 \mathrm{~mm}$, gas flow rate: $5.344 \mathrm{Nl} / \mathrm{min}$, submergence depth of the SEN: $100 \mathrm{~mm}$, water flow rate: (a) $2.0 \mathrm{~m}^{3} /$ hour, (b) $6.6 \mathrm{~m}^{3} /$ hour

Fig.9 Fluid flow pattern in the $200 \mathrm{~mm} \times 1250 \mathrm{~mm}$ mold progressing from the single roll (a) to the double roll (b)

Fig.10 Factors affecting the depth of the lower roll center

Fig.11 Example measured level fluctuation signal (a) split into low frequency (b) and high frequency (c) components

Fig.12 Level fluctuations with different gas flow rates and mold widths

Fig.13 Effect of casting speed on the level fluctuations 
Fig.14 Effect of submergence depth on the level fluctuation in the mold

Fig.15 Effect of SEN outport angle on the level fluctuation in the mold

Fig.16 Effect of inner bore diameter of SEN on level fluctuations in the mold

Fig.17 Effect of port-to-bore area ratio $\psi$ on mold level fluctuations

Fig.18 Factors affecting the impingement pressure

Fig.19 Measured level fluctuation (a), impingement pressure (b) and the location of the lower roll center (c) with different SEN bottom shape for the water mode of the $200 \mathrm{~mm} \times 1250 \mathrm{~mm}$ steel mold

Fig.20 Typical random walk trajectories of 10 bubbles with the size of $1 \mathrm{~mm}$ (a) and $5 \mathrm{~mm}$ (b) in the water mold of Fig.4

Fig.21 Burning of mold flux at $1 / 4$ width the mold top surface during a slab casting process ${ }^{[113]}$

Fig.22 Typical large inclusions in the slab extracted by the Slime method

Fig.23 Total oxygen and nitrogen content in the mold (up figure) and $>50 \mu \mathrm{m}$ inclusions in the slab by Slime test (lower figure) 
Table I Relationship between the flow rate and the casting speed

\begin{tabular}{|c|c|c|c|c|c|c|c|}
\hline & $\begin{array}{c}\text { Casting speed } \\
(\mathrm{m} / \mathrm{min})\end{array}$ & 0.8 & 1.0 & 1.2 & 1.4 & 1.6 & 1.8 \\
\hline $\begin{array}{c}200 \mathrm{~mm} \times 900 \mathrm{~mm} \\
\text { slab }\end{array}$ & $\begin{array}{c}\text { Steel throughput } \\
\left(\mathrm{m}^{3} / \text { hour }\right)\end{array}$ & 9.60 & 11.90 & 14.28 & 16.66 & 19.04 & 21.41 \\
\cline { 2 - 8 } & $\begin{array}{c}\text { Water } \\
\text { throughput } \\
\left(\mathrm{m}^{3} / \text { hour }\right)\end{array}$ & 2.68 & 3.32 & 3.98 & 4.65 & 5.31 & 5.98 \\
\hline $\begin{array}{c}200 \mathrm{~mm} \times 1250 \mathrm{~mm} \\
\text { slab }\end{array}$ & $\begin{array}{c}\text { Steel throughput } \\
\left(\mathrm{m}^{3} / \text { hour }\right)\end{array}$ & 13.22 & 16.52 & 19.83 & 23.14 & 26.44 & 30.00 \\
\cline { 2 - 8 } & $\begin{array}{c}\text { Water } \\
\text { throughput } \\
\text { (m³/hour) }\end{array}$ & 3.69 & 4.61 & 5.53 & 6.46 & 7.38 & 8.37 \\
\hline
\end{tabular}


Table II Parameters used in the water model

\begin{tabular}{l|l}
\hline Casting speed $(\mathrm{m} / \mathrm{min})$ & $1.0,1.2,1.4,1.6,1.8$
\end{tabular}

\begin{tabular}{ll}
\hline SEN submergence depth (mm) & $40,70,700,130,160$
\end{tabular}

Gas flow rate (Nl/min) $\quad 0,4.58,9.16,12.74,18.32$

\begin{tabular}{l|l}
\hline SEN outport angle & $+5^{0},-0^{\circ},-5^{0},-15^{0,}-25^{\circ}$
\end{tabular}

\begin{tabular}{ll}
\hline Bore diameter of the SEN (mm) & $30,35,40,45,50$
\end{tabular}

\begin{tabular}{|l|l}
\hline Ports to bore area ratio $\psi$ & $1.5,1.73,2.0,2.27,2.5$
\end{tabular} 
Table III Orthogonal array $L_{9}\left(3^{4}\right)$ : nine combinations for four factors with three values

\begin{tabular}{|c|c|c|c|c|}
\hline Combination & Factor 1 & Factor 2 & Factor 3 & Factor 4 \\
\hline $1^{\text {st }}$ & 1 & 1 & 1 & 1 \\
\hline $2^{\text {nd }}$ & 1 & 2 & 2 & 2 \\
\hline $3^{\text {rd }}$ & 1 & 3 & 3 & 3 \\
\hline $4^{\text {th }}$ & 2 & 1 & 3 & 1 \\
\hline $5^{\text {th }}$ & 2 & 2 & 1 & 2 \\
\hline $6^{\text {th }}$ & 2 & 3 & 3 & 2 \\
\hline $7^{\text {th }}$ & 3 & 1 & 1 & 3 \\
\hline $8^{\text {th }}$ & 3 & 2 & 2 & 1 \\
\hline $9^{\text {th }}$ & 3 & 3 & & \\
\hline
\end{tabular}


Table IV Fluid flow pattern in the water model the mold

\begin{tabular}{|c|c|c|c|c|c|c|c|}
\hline \multirow{2}{*}{$\begin{array}{l}\text { Strand } \\
\text { size }\end{array}$} & \multirow{2}{*}{$\begin{array}{l}\text { Casting } \\
\text { speed }\end{array}$} & \multirow{2}{*}{$\begin{array}{l}\text { Gas flow } \\
\text { rate }\end{array}$} & \multicolumn{4}{|c|}{ SEN } & \multirow[t]{2}{*}{ Flow pattern } \\
\hline & & & $\begin{array}{l}\text { Submergence } \\
\text { depth }\end{array}$ & $\begin{array}{c}\text { Outport } \\
\text { angle }\end{array}$ & Bore size & $\begin{array}{c}\text { Area ratio } \\
\qquad \psi\end{array}$ & \\
\hline \multirow{6}{*}{$\begin{array}{l}200 \mathrm{~mm} \\
\times 900 \mathrm{~mm}\end{array}$} & $1.0 \mathrm{~m} / \mathrm{min}$ & $4.6 \mathrm{Nl} / \mathrm{min}$ & $70 \mathrm{~mm}$ & $0^{\circ}$ & $35 \mathrm{~mm}$ & 1.73 & Double roll \\
\hline & $1.2 \mathrm{~m} / \mathrm{min}$ & $4.6 \mathrm{Nl} / \mathrm{min}$ & $100 \mathrm{~mm}$ & $-15^{\circ}$ & $50 \mathrm{~mm}$ & 1.5 & Single roll \\
\hline & $1.4 \mathrm{~m} / \mathrm{min}$ & $13.7 \mathrm{Nl} / \mathrm{min}$ & $40 \mathrm{~mm}$ & $-5^{\circ}$ & $50 \mathrm{~mm}$ & 1.73 & Single roll \\
\hline & $1.8 \mathrm{~m} / \mathrm{min}$ & $9.2 \mathrm{Nl} / \mathrm{min}$ & $70 \mathrm{~mm}$ & $+5^{0}$ & $50 \mathrm{~mm}$ & 2.27 & Double roll \\
\hline & $1.8 \mathrm{~m} / \mathrm{min}$ & $13.7 \mathrm{Nl} / \mathrm{min}$ & $100 \mathrm{~mm}$ & $0^{\circ}$ & $30 \mathrm{~mm}$ & 2.5 & Double roll \\
\hline & $1.8 \mathrm{~m} / \mathrm{min}$ & $18.3 \mathrm{Nl} / \mathrm{min}$ & $130 \mathrm{~mm}$ & $-5^{0}$ & $35 \mathrm{~mm}$ & 1.5 & Double roll \\
\hline \multirow{7}{*}{$\begin{array}{l}200 \mathrm{~mm} \\
\times 1250 \\
\mathrm{~mm}\end{array}$} & $0.8 \mathrm{~m} / \mathrm{min}$ & $0 \mathrm{Nl} / \mathrm{min}$ & $40 \mathrm{~mm}$ & $+5^{0}$ & $30 \mathrm{~mm}$ & 1.5 & Double roll \\
\hline & $0.8 \mathrm{~m} / \mathrm{min}$ & $9.2 \mathrm{Nl} / \mathrm{min}$ & $100 \mathrm{~mm}$ & $-5^{\circ}$ & $40 \mathrm{~mm}$ & 2.0 & Single roll \\
\hline & $1.0 \mathrm{~m} / \mathrm{min}$ & $0 \mathrm{Nl} / \mathrm{min}$ & $70 \mathrm{~mm}$ & $-5^{0}$ & $45 \mathrm{~mm}$ & 2.5 & e roll \\
\hline & $1.0 \mathrm{~m} / \mathrm{min}$ & $4.6 \mathrm{Nl} / \mathrm{min}$ & $100 \mathrm{~mm}$ & $-15^{\circ}$ & $50 \mathrm{~mm}$ & 1.5 & roll \\
\hline & $1.0 \mathrm{~m} / \mathrm{min}$ & $18.3 \mathrm{Nl} / \mathrm{min}$ & $40 \mathrm{~mm}$ & $0^{\circ}$ & $40 \mathrm{~mm}$ & 2.27 & Single roll \\
\hline & $1.2 \mathrm{~m} / \mathrm{min}$ & $9.2 \mathrm{Nl} / \mathrm{min}$ & $160 \mathrm{~mm}$ & $0^{\circ}$ & $45 \mathrm{~mm}$ & 1.5 & Double roll \\
\hline & $1.2 \mathrm{~m} / \mathrm{min}$ & $13.7 \mathrm{Nl} / \mathrm{min}$ & $40 \mathrm{~mm}$ & $-5^{0}$ & $50 \mathrm{~mm}$ & 1.73 & Single roll \\
\hline
\end{tabular}


Table $\mathrm{V}$ Composition of typical large inclusions in the slab from mold slag entrainment

\begin{tabular}{|c|l|l|}
\hline 1 & $\mathrm{Al}_{2} \mathrm{O}_{3} 40.11 \%, \mathrm{CaO} 33.70 \%, \mathrm{SiO}_{2} 20.02 \%, \mathbf{N a}_{\mathbf{2}} \mathbf{O} \mathbf{4 . 6 2} \mathbf{6}, \mathbf{L a}_{\mathbf{2}} \mathbf{O}_{3} \mathbf{1 . 5 6} \%$ \\
\hline 2 & $\mathrm{Al}_{2} \mathrm{O}_{3} 65.30 \%, \mathrm{FeO} 26.49 \%, \mathrm{CaO} 2.1 \%, \mathrm{SiO}_{2} 2.84 \%, \mathrm{MnO} 0.85 \%, \mathrm{TiO}_{2} 0.30 \%, \mathrm{BaO}$ \\
& $0.13 \%, \mathbf{L a}_{2} \mathbf{O}_{3} \mathbf{0 . 0 6 5} \%$
\end{tabular}


Table VI Area percentage (\%) of inclusions by microscope observation

\begin{tabular}{|l|l|l|l|l|l|l|}
\hline Samples & 1 & 2 & 3 & 4 & 5 & Mean \\
\hline Strand 1 & 0.1789 & 0.1994 & 0.0890 & 0.0508 & 0.0481 & 0.11324 \\
\hline Strand 2 & 0.1991 & 0.1906 & 0.1083 & 0.0764 & 0.0786 & 0.1306 \\
\hline
\end{tabular}


Table VII Measured thickness of liquid slag layer on the top of the mold (mm)

\begin{tabular}{|l|c|c|c|c|}
\hline & Near the meniscus & $1 / 4$ width & Near the SEN & $\begin{array}{l}\text { Mean } \\
\text { thickness }\end{array}$ \\
\hline \multirow{3}{*}{ Strand 1} & 14 & 13 & 12 & \multirow{2}{*}{12.8} \\
& 14 & 11 & 10 & \\
\cline { 2 - 4 } & 15 & 13 & 13 & \\
\hline Strand 2 & 11 & 10 & 10 & 10.3 \\
\hline
\end{tabular}


Table VIII Measured $\mathrm{Al}_{2} \mathrm{O}_{3}$ fraction in the liquid flux of the mold (initial $\mathrm{Al}_{2} \mathrm{O}_{3}$ content in the flux: $2.84 \%)$

\begin{tabular}{|c|c|c|c|c|c|}
\hline & \multicolumn{4}{|c|}{$\mathrm{Al}_{2} \mathrm{O}_{3}$ fraction in the liquid slag (\%) } & \multirow{2}{*}{$\begin{array}{c}\Delta \mathrm{Al}_{2} \mathrm{O}_{3} \text { in liquid slag } \\
(\%)\end{array}$} \\
\hline & Heat 1 & Heat 2 & Heat 3 & Mean & \\
\hline Strand 1 & 9.08 & 6.89 & 5.71 & 7.23 & 4.39 \\
\hline Strand 2 & 7.73 & 7.35 & 9.19 & 8.09 & 5.25 \\
\hline
\end{tabular}

Table VIII Estimated total oxygen removal in the steel by SEN and the mold

\begin{tabular}{|c|c|c|c|c|c|c|}
\hline & $h(\mathrm{~m})$ & $W_{\mathrm{LS}}(\mathrm{kg})$ & $\Delta \mathrm{Al}_{2} \mathrm{O}_{3}(\%)$ & $\mathrm{W}_{\text {Al2O3 }}(\mathrm{kg})$ & $\mathrm{M}_{\text {Al2O3 }}(\mathrm{kg})$ & $\Delta[\mathrm{O}](\mathrm{ppm})$ \\
\hline Strand 1 & $10.59 \mathrm{~kg}$ & 11.20 & 4.39 & 0.492 & 2.634 & $12.26 \mathrm{ppm}$ \\
\hline Strand 2 & $8.46 \mathrm{~kg}$ & 9.01 & 5.25 & 0.473 & 3.15 & $14.21 \mathrm{ppm}$ \\
\hline
\end{tabular}




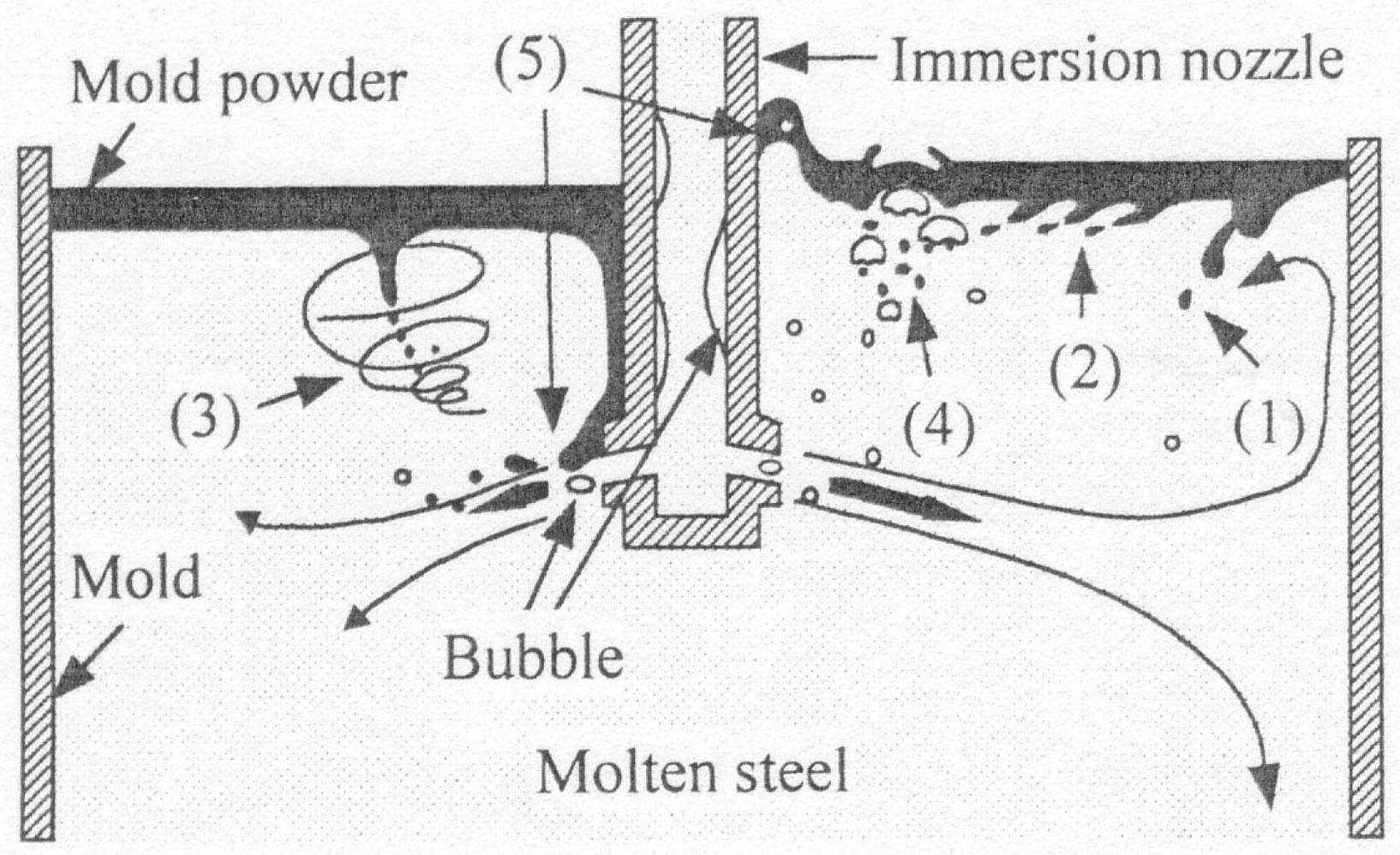

Fig.1 Mechanisms of slag entrainment in the continuous casting mold ${ }^{[10]}$ 

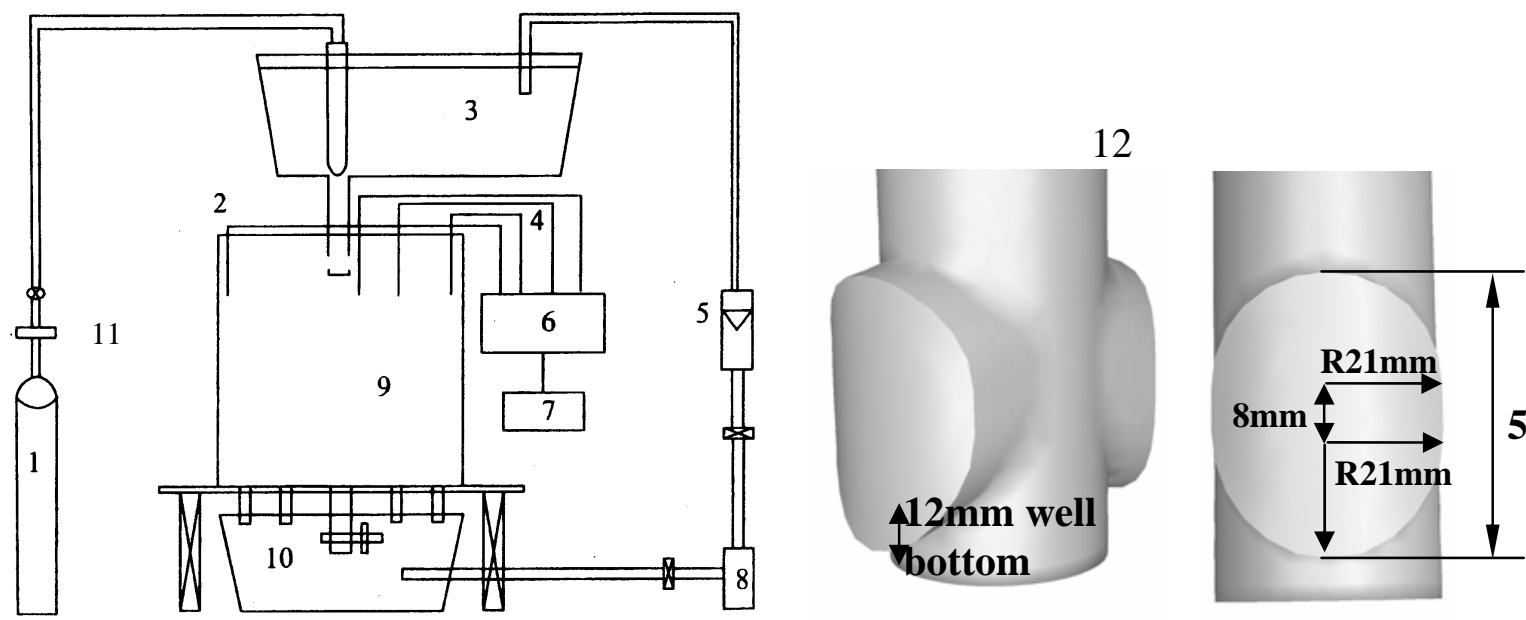

$50 \mathrm{~mm}$

Fig.2 Schematic of the water model experiment (1: $\mathrm{N}_{2}$ tank, 2: pressure measurement probe, 3 : tundish, 4: level fluctuation measurement probes, 5: water flow meter, 6: Data collection system, 7: Computer, 8: pump, 9: mold, 10: water collection tank, 11: gas flow meter, 12: one example dimension of the SEN outports) 


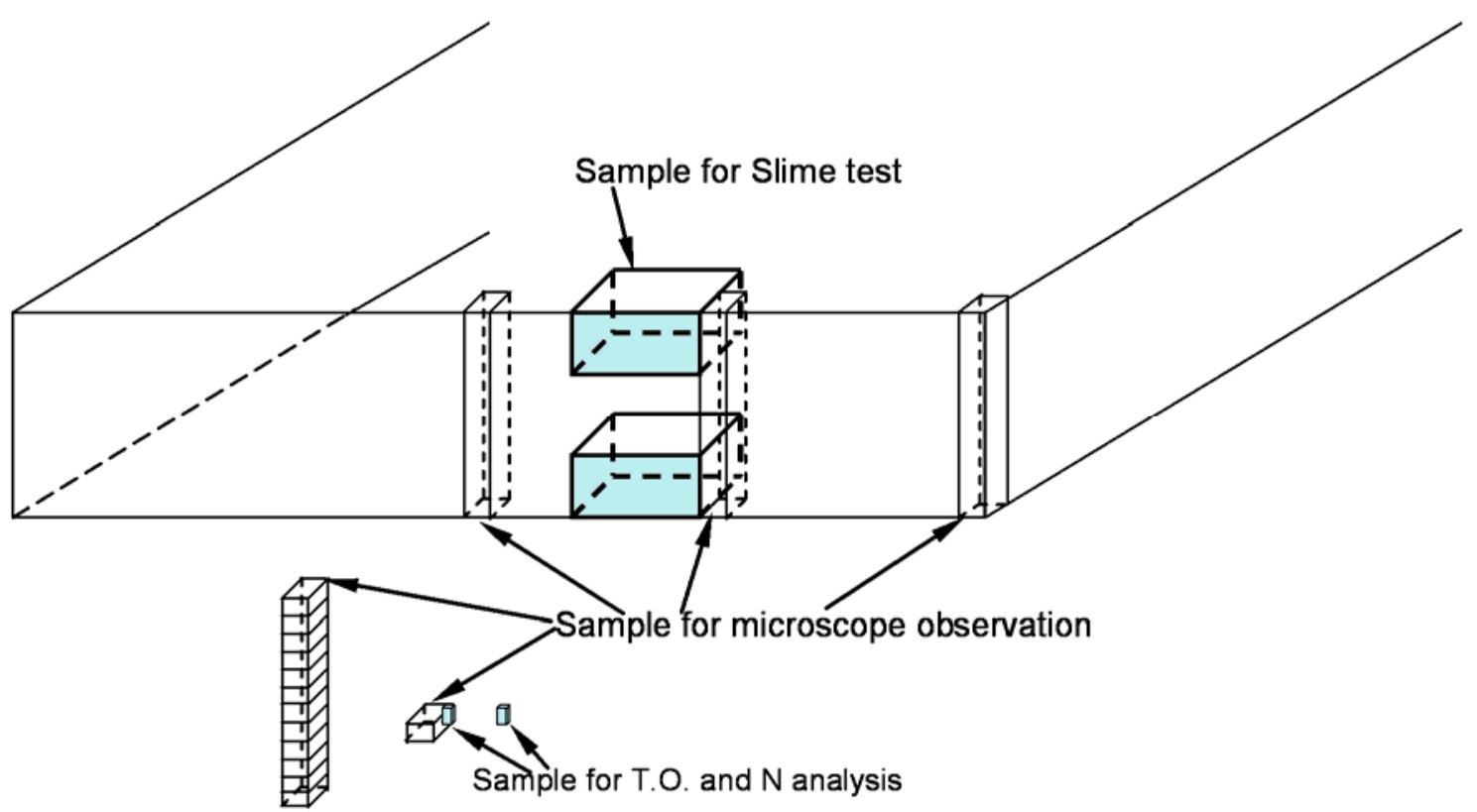

Fig.3 Sampling places at continuous casting slab 


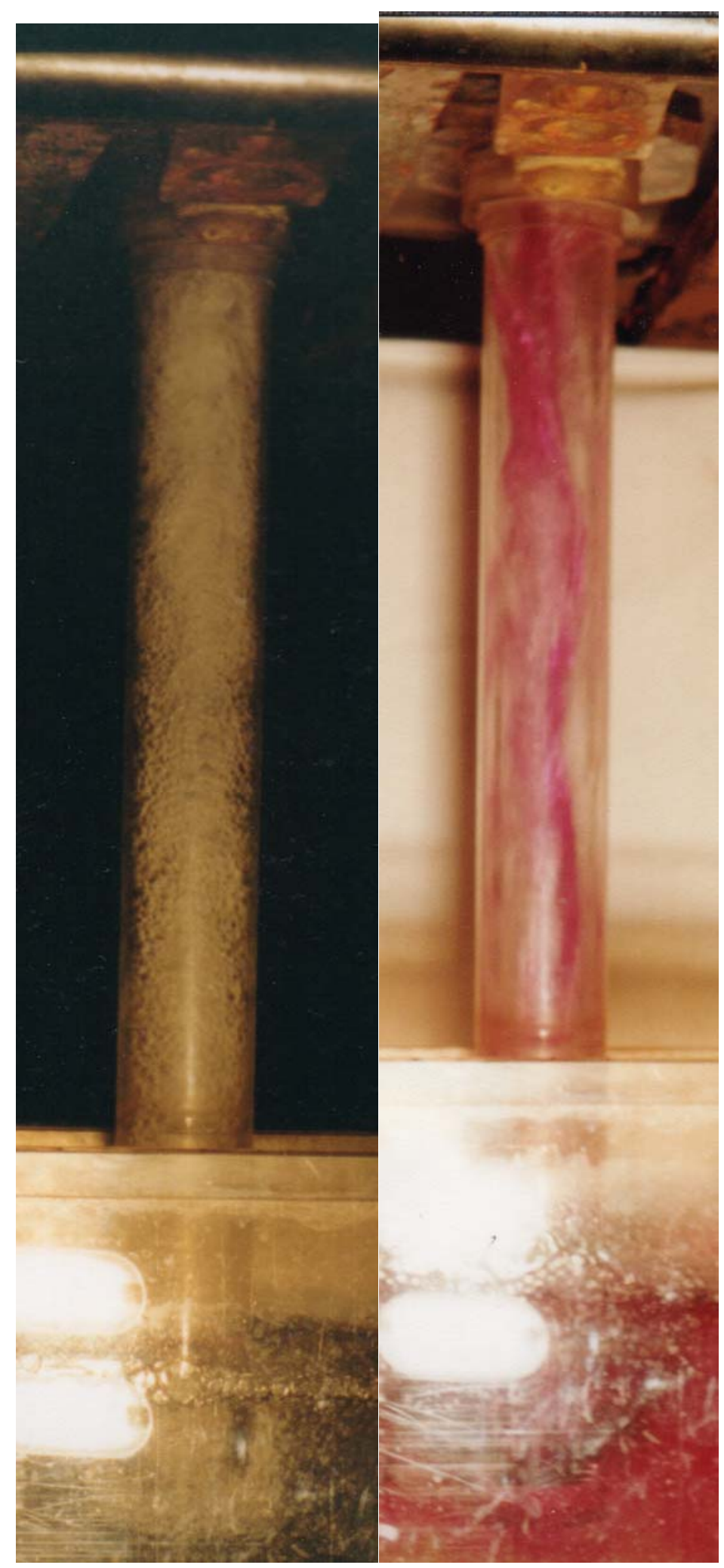

(a) bubbly flow

(b) annular flow

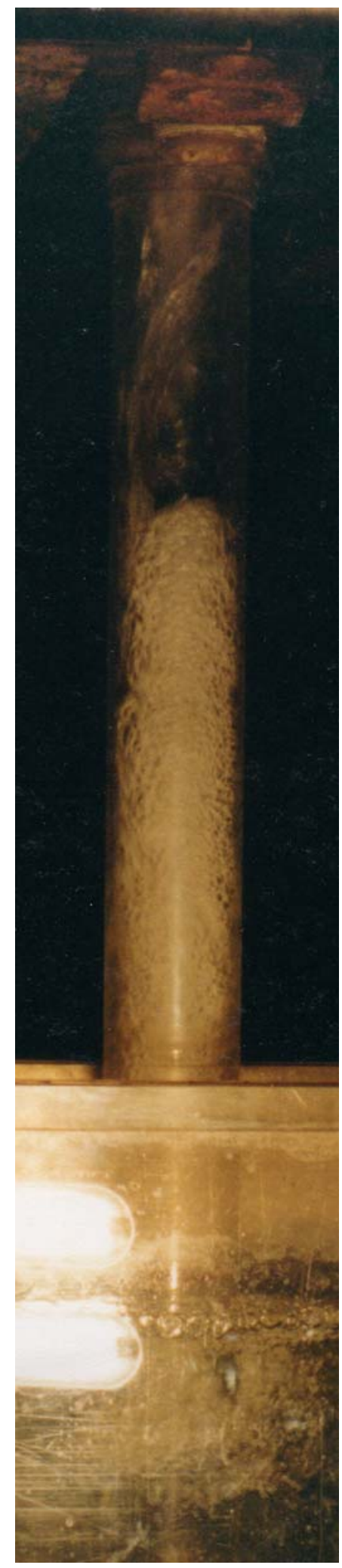

(c) critical flow

Fig.4 The multiphase fluid flow pattern in the SEN with $45 \mathrm{~mm}$ bore diameter 


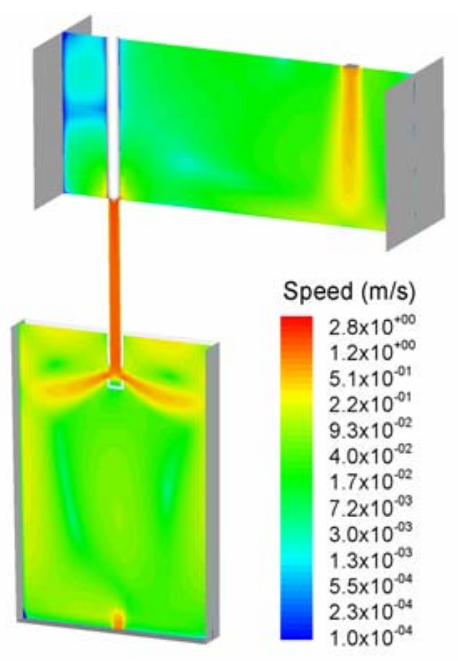

(a) Speed contour on center face across tundish, nozzle and mold

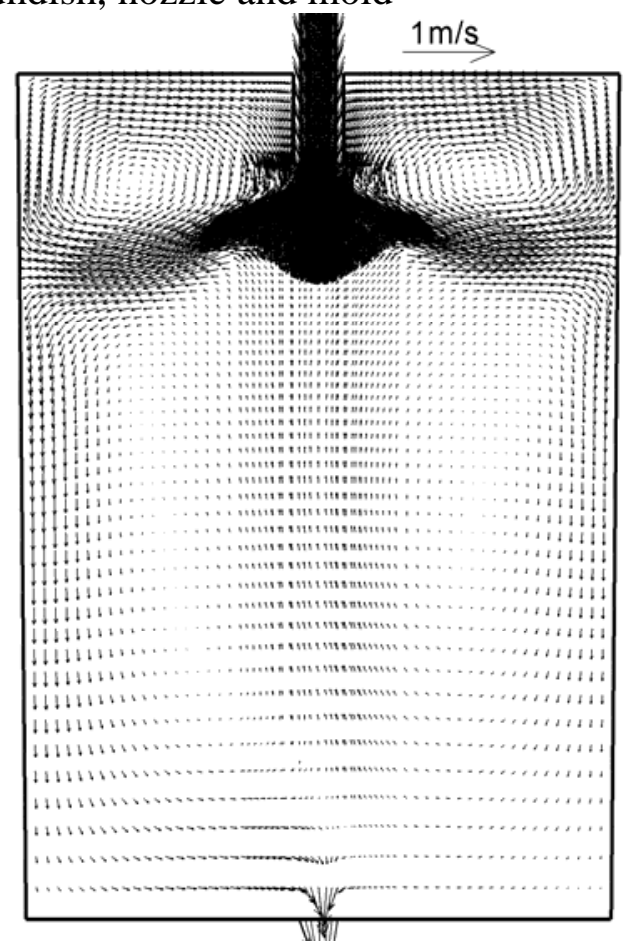

(c) Velocity vectors on the center plane of the mold

Fig54 Calculated single phase fluid flow in the tundish, the SEN and the mold (water model of the $200 \mathrm{~mm} \times 1250$ mold, casting speed: $1.4 \mathrm{~m} / \mathrm{min}$, tundish inlet velocity: $0.731 \mathrm{~m} / \mathrm{s}$, inlet turbulent energy: $0.004 \mathrm{~m}^{2} / \mathrm{s}^{2}$, and its dissipation rate: $0.03 \mathrm{~m}^{2} / \mathrm{s}^{3}$, SEN bore diameter: $45 \mathrm{~mm}$, outport angle: down $15^{\circ}$, Submergence depth of the SEN: $130 \mathrm{~mm}$, water height in the tundish: 600mm, tundish length: $1400 \mathrm{~mm}$, tundish thickness: 400mm) 


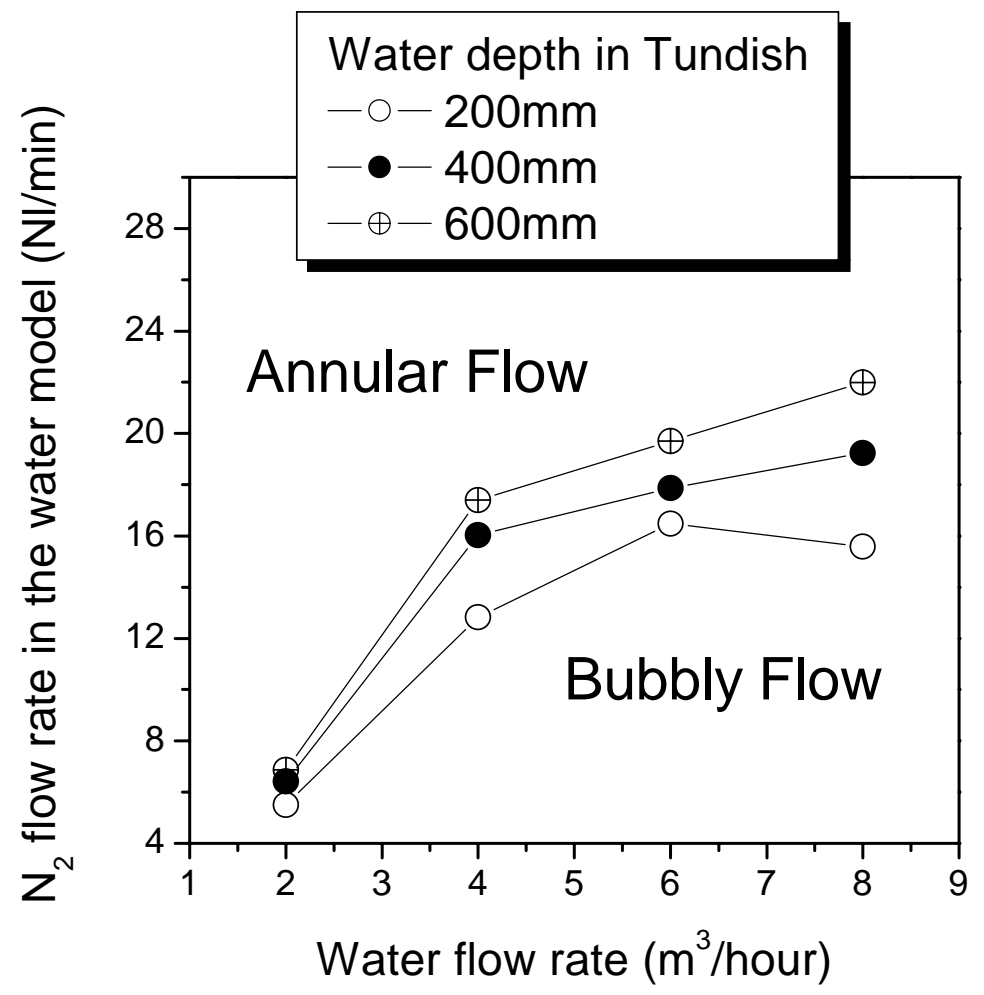

Fig.6 The conditions to achieve annular flow or the bubbly flow in a $45 \mathrm{~mm}$ SEN (water model) 

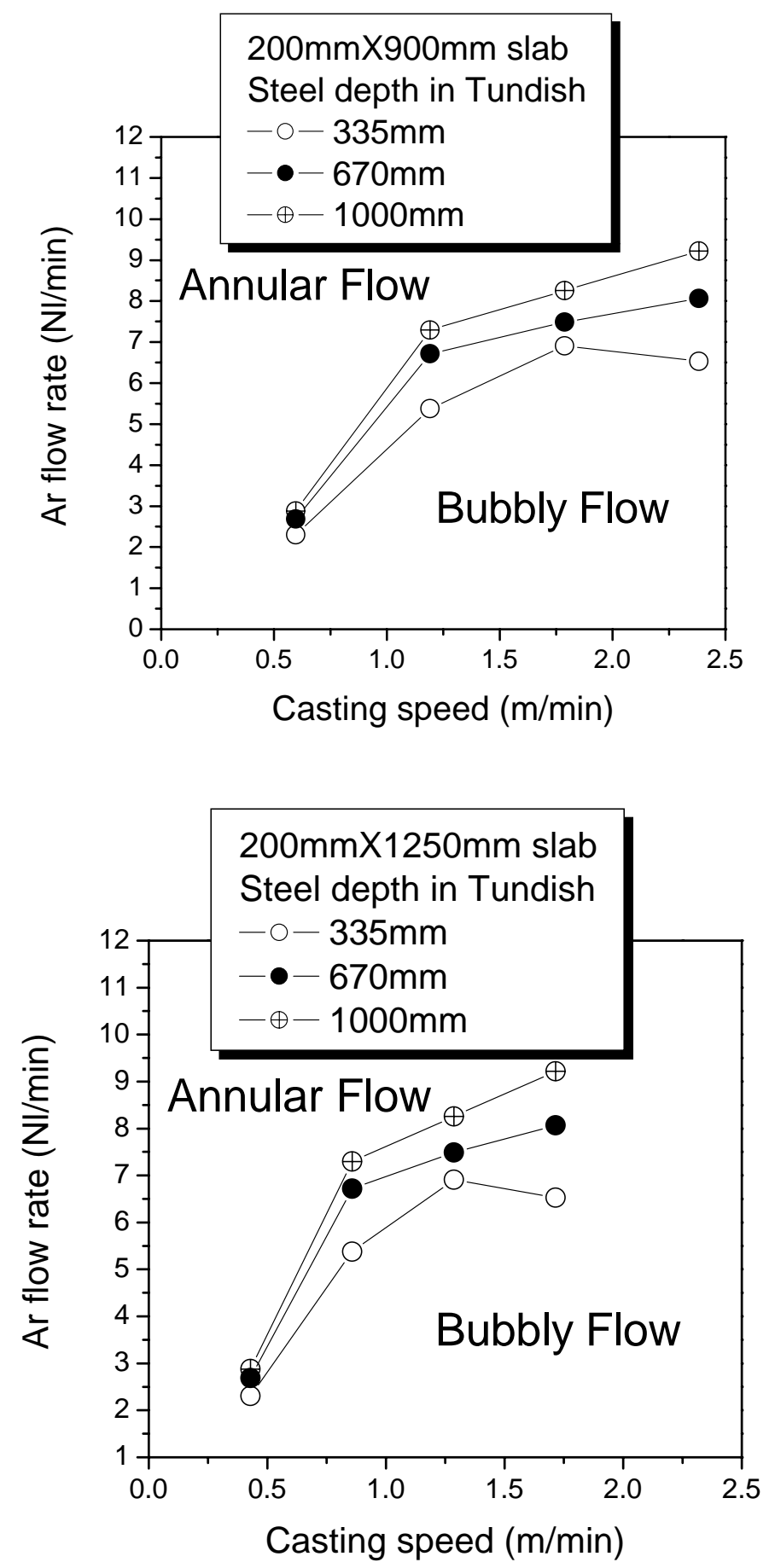

Fig.7 The conditions to change annular flow to bubbly flow in a $75 \mathrm{~mm}$ SEN (liquid steel) for different size slabs 


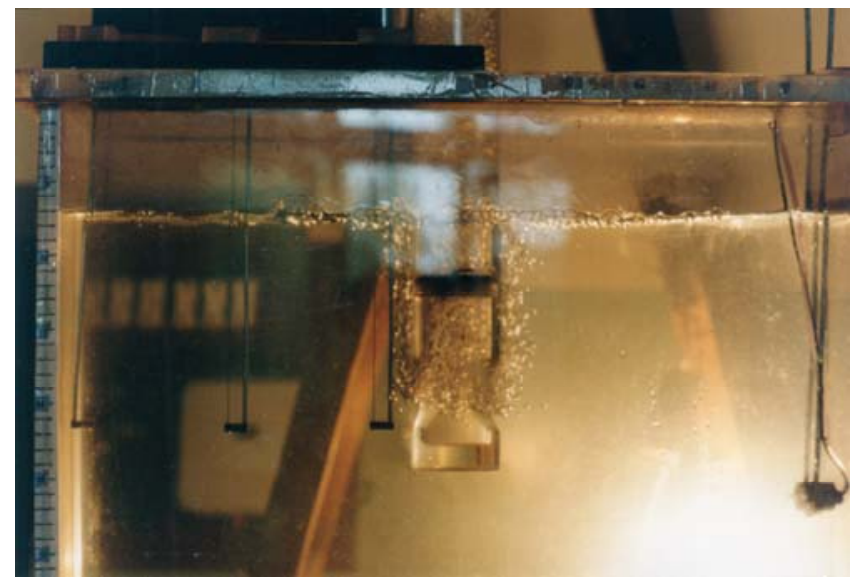

(a)

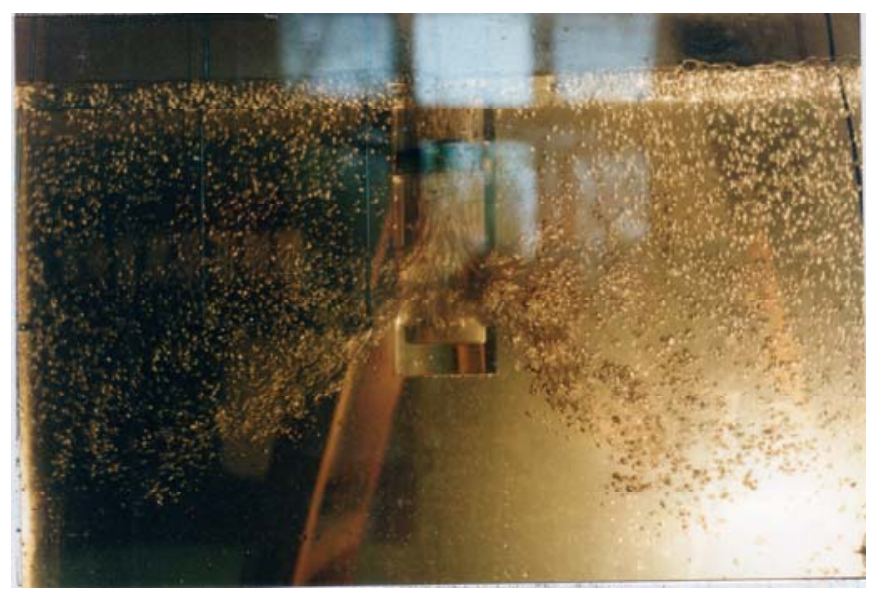

(b)

Fig. 8 Two phase fluid flow pattern in the water model of the $200 \mathrm{~mm} \times 1250 \mathrm{~mm}$ steel slab (bore diameter of the SEN: $45 \mathrm{~mm}$, gas flow rate: $5.344 \mathrm{Nl} / \mathrm{min}$, submergence depth of the SEN: $100 \mathrm{~mm}$, water flow rate: (a) $2.0 \mathrm{~m}^{3} /$ hour, (b) $6.6 \mathrm{~m}^{3} /$ hour 


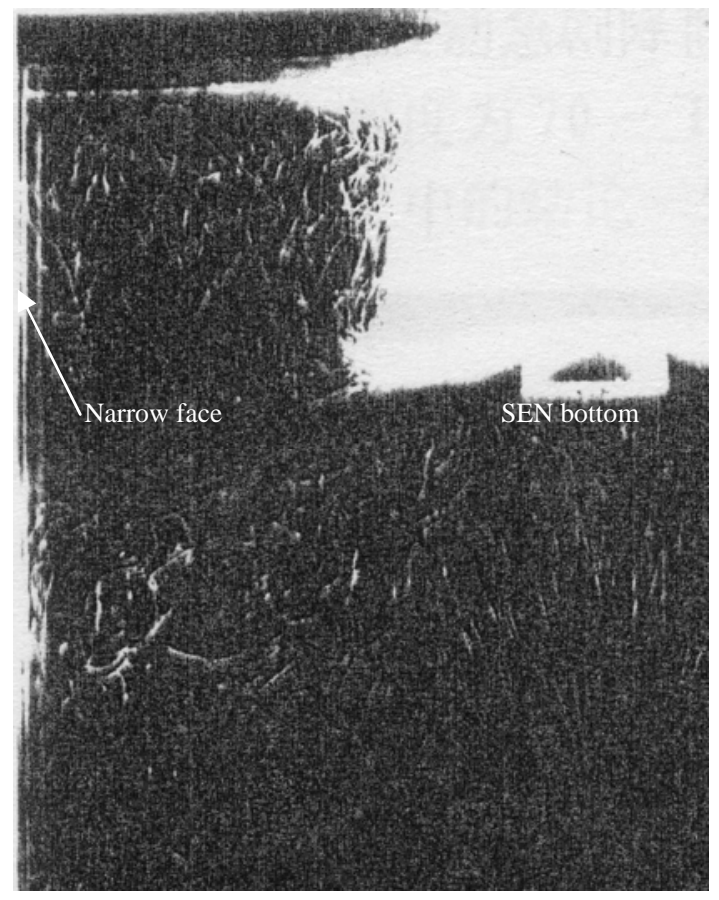

(a)

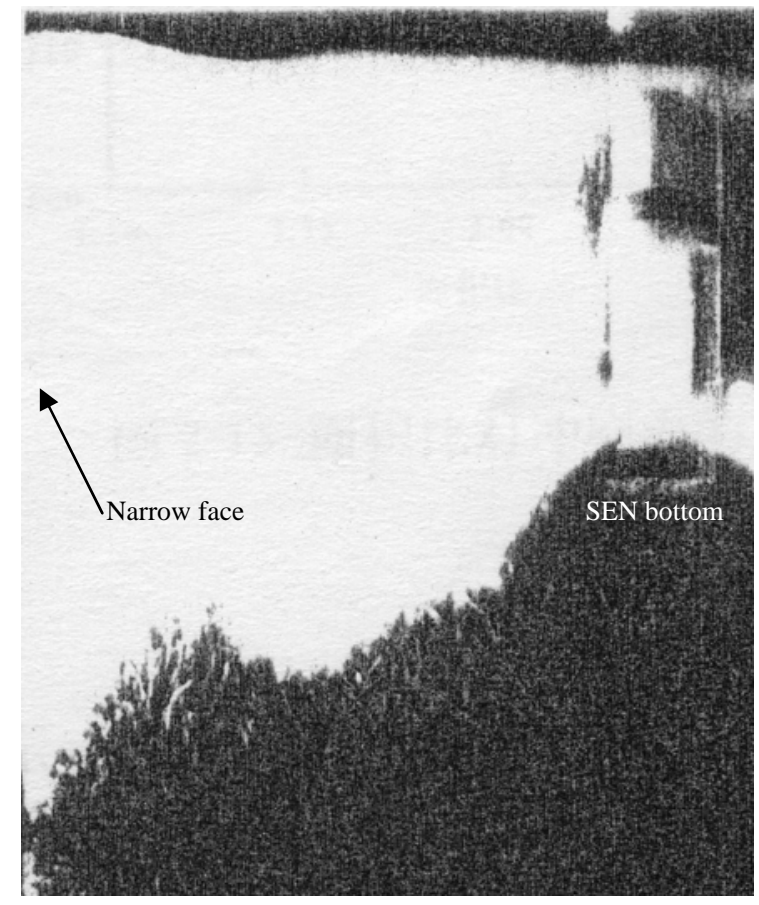

(b)

\begin{tabular}{|c|c|c|c|c|c|c|}
\hline & Casting speed & $\begin{array}{l}\text { Submergence } \\
\text { depth of SEN }\end{array}$ & $\begin{array}{l}\text { Gas flow } \\
\text { rate }\end{array}$ & $\begin{array}{l}\text { Outport angle } \\
\text { of SEN }\end{array}$ & $\begin{array}{l}\text { Bore size of } \\
\text { the SEN }\end{array}$ & $\begin{array}{l}\text { Port to bore } \\
\text { area ratio } \psi\end{array}$ \\
\hline & $1.2 \mathrm{n}$ & $100 \mathrm{~mm}$ & $4.6 \mathrm{Nl} / \mathrm{min}$ & $-15^{\circ}$ & & 0.67 \\
\hline (b) & $1.8 \mathrm{~m} / \mathrm{min}$ & $130 \mathrm{~mm}$ & $18.3 \mathrm{Nl} / \mathrm{min}$ & $-5^{0}$ & $35 \mathrm{~mm}$ & 0.67 \\
\hline
\end{tabular}

Fig.9 Fluid flow pattern in the $200 \mathrm{~mm} \times 1250 \mathrm{~mm}$ mold progressing from the single roll (a) to the double roll (b) 


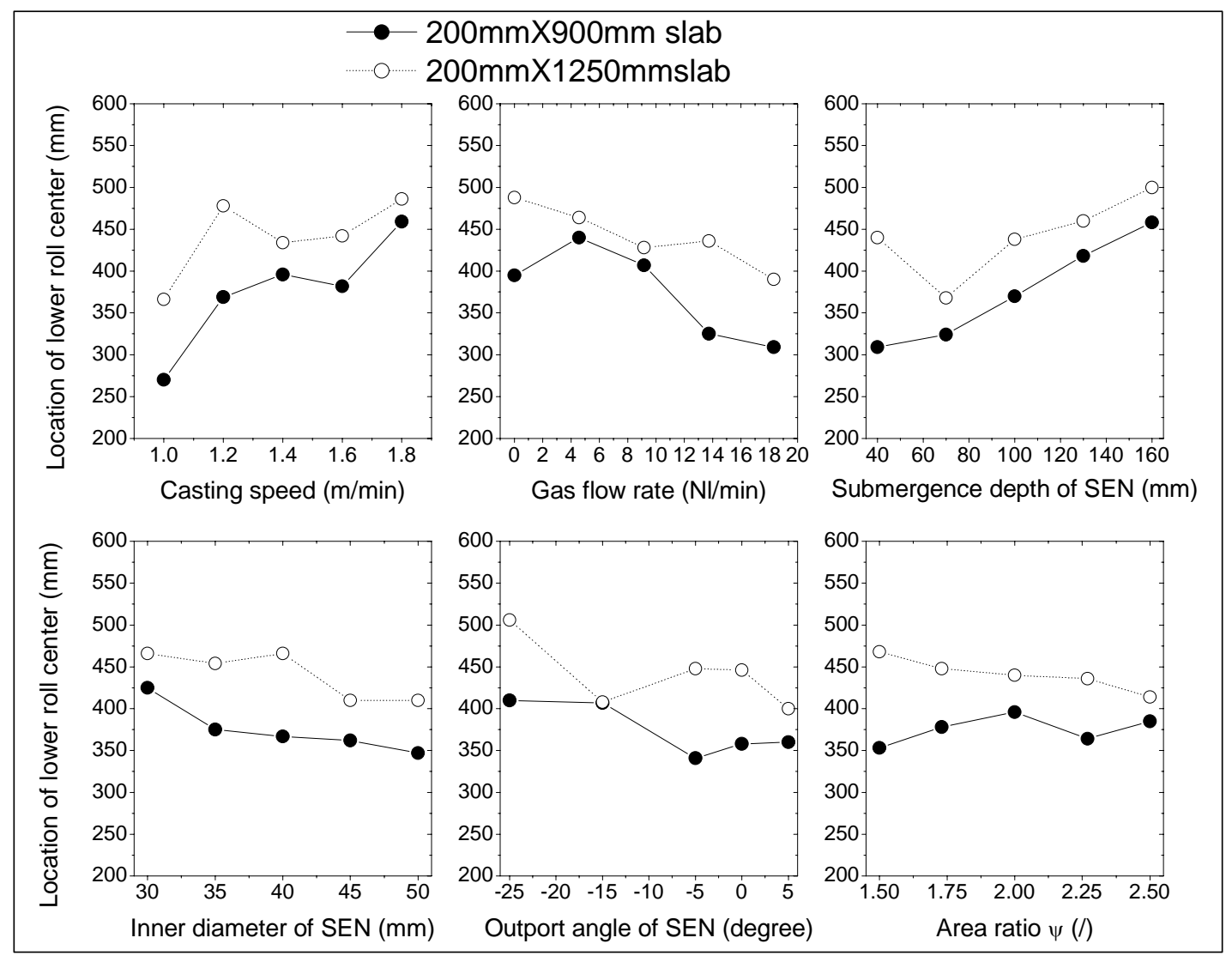

Fig10 Factors affecting the depth of the lower roll center 

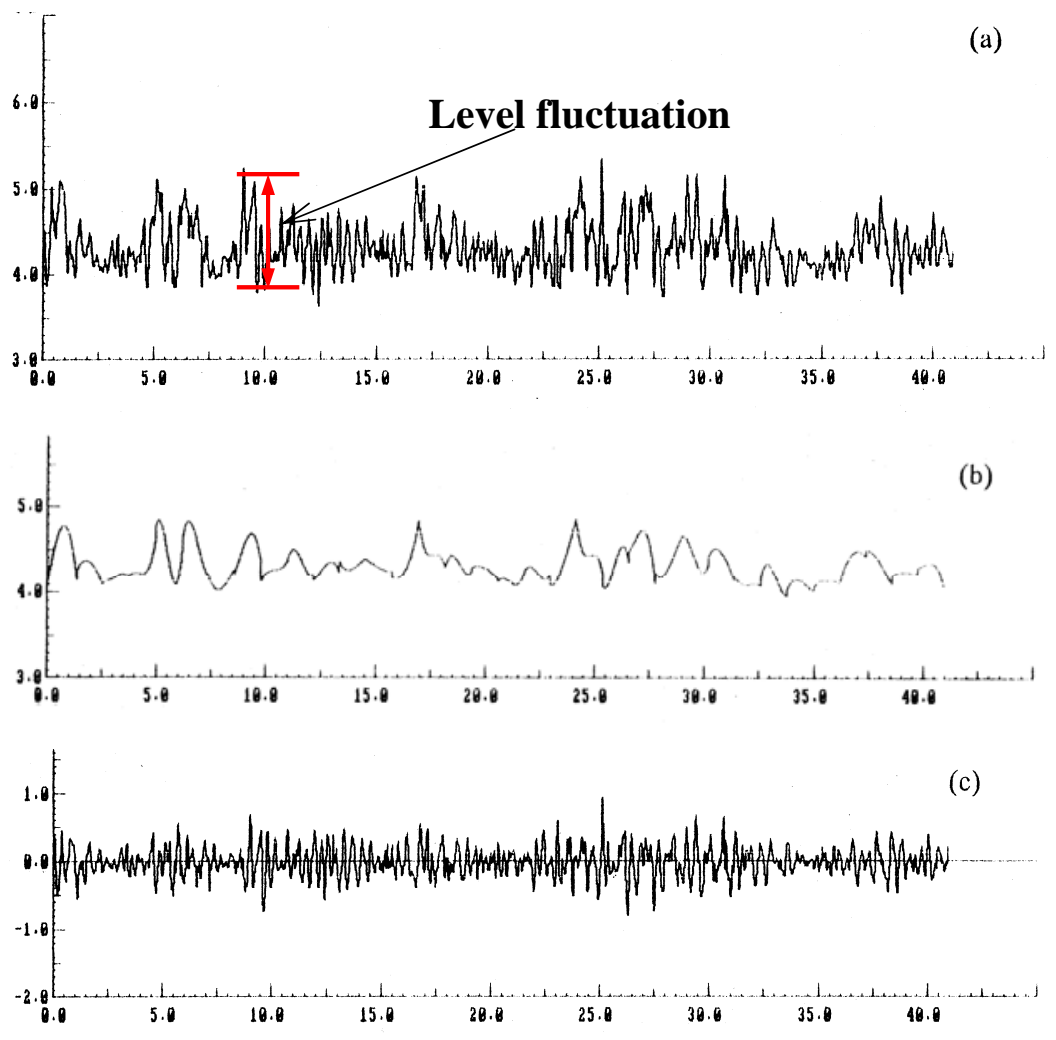

Fig.11 Example measured level fluctuation signal (a) split into low frequency (b) and high frequency (c) components 

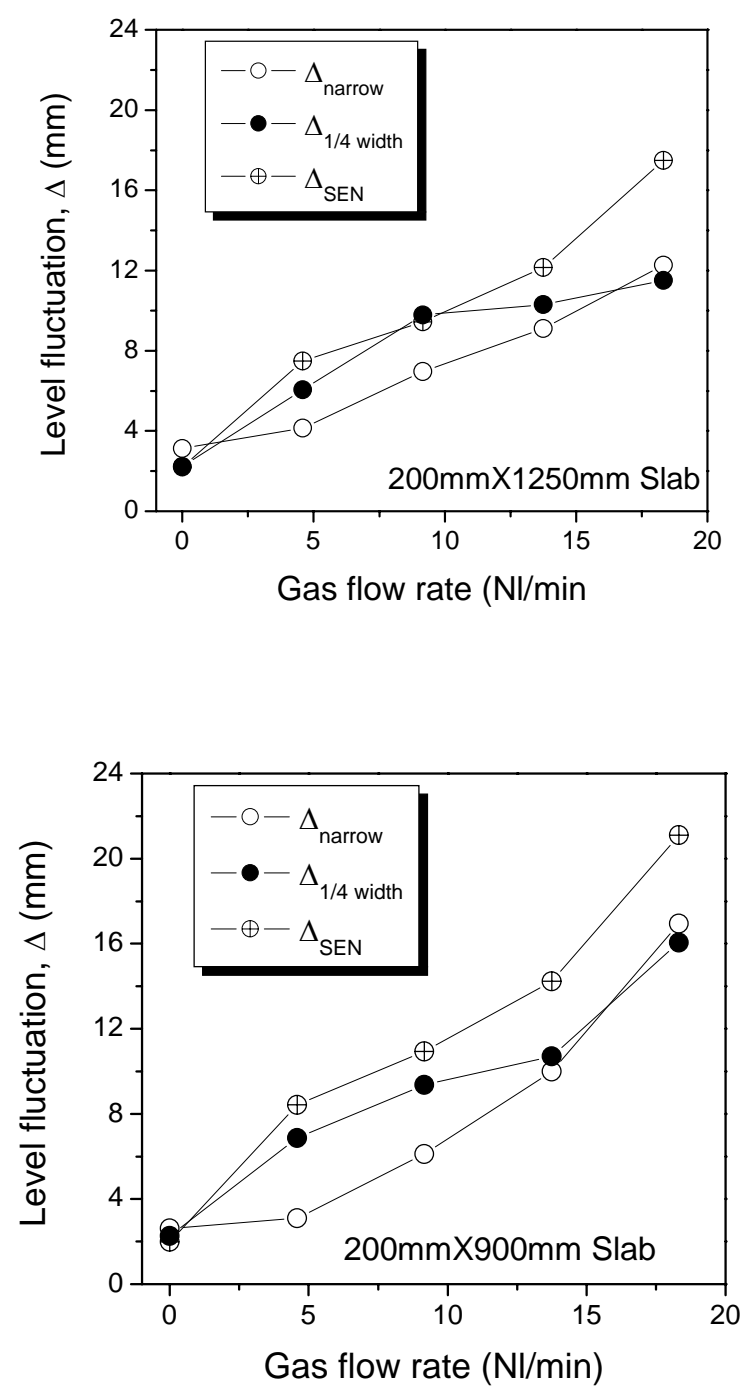

Fig. 12 Level fluctuations with different gas flow rates and mold widths 

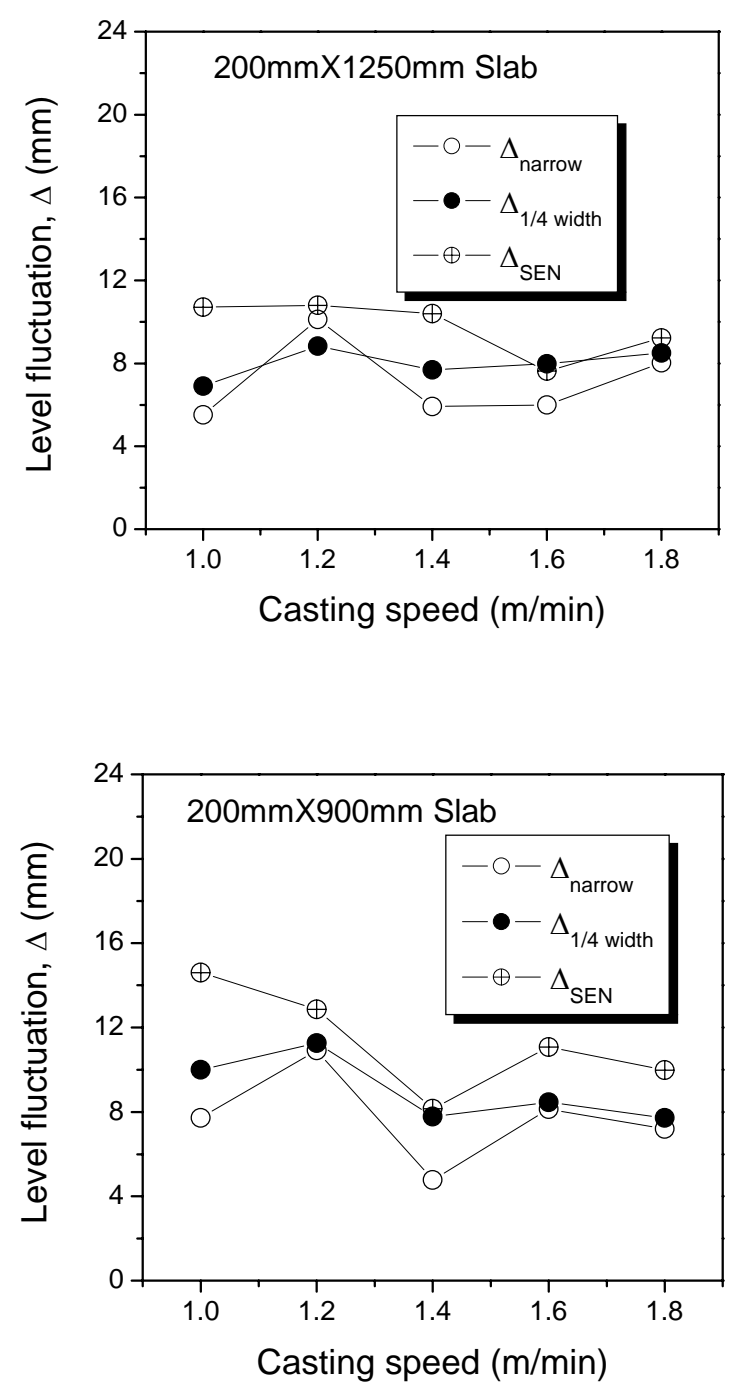

Fig. 13Effect of casting speed on the level fluctuations 

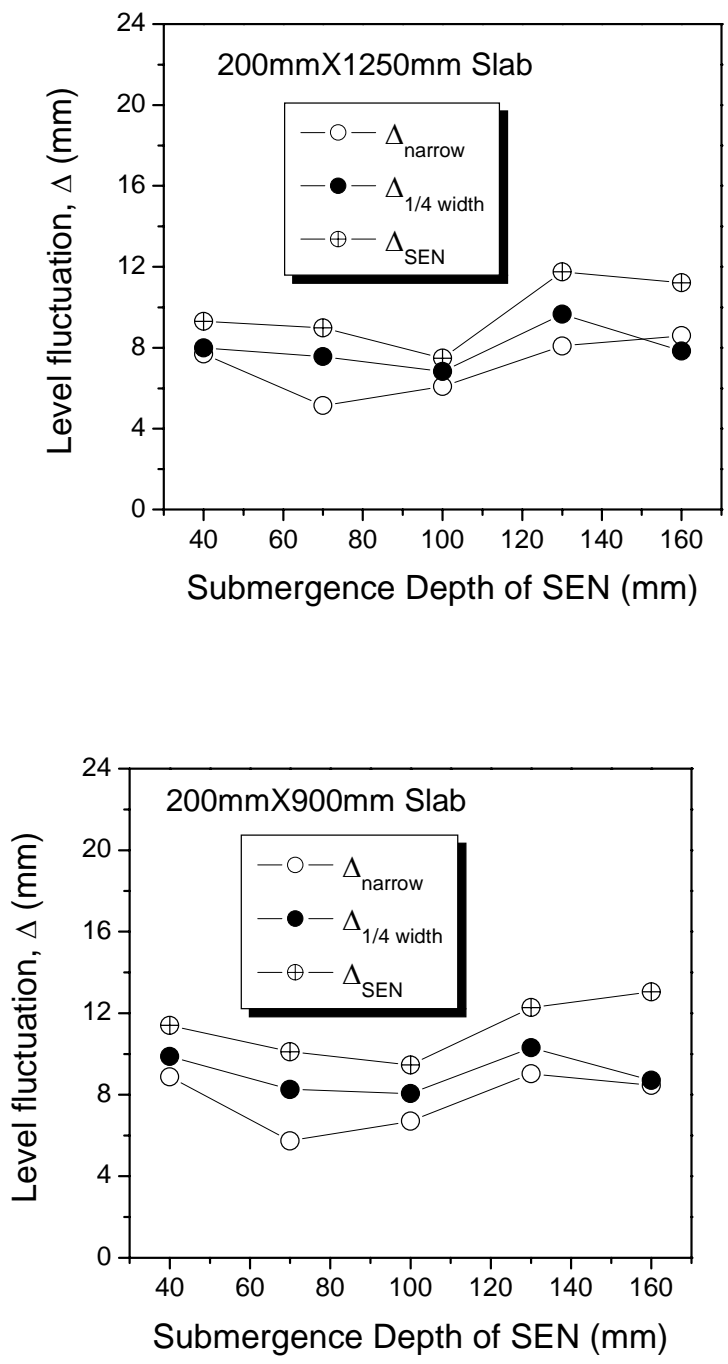

Fig.14 Effect of submergence depth on the level fluctuation in the mold 

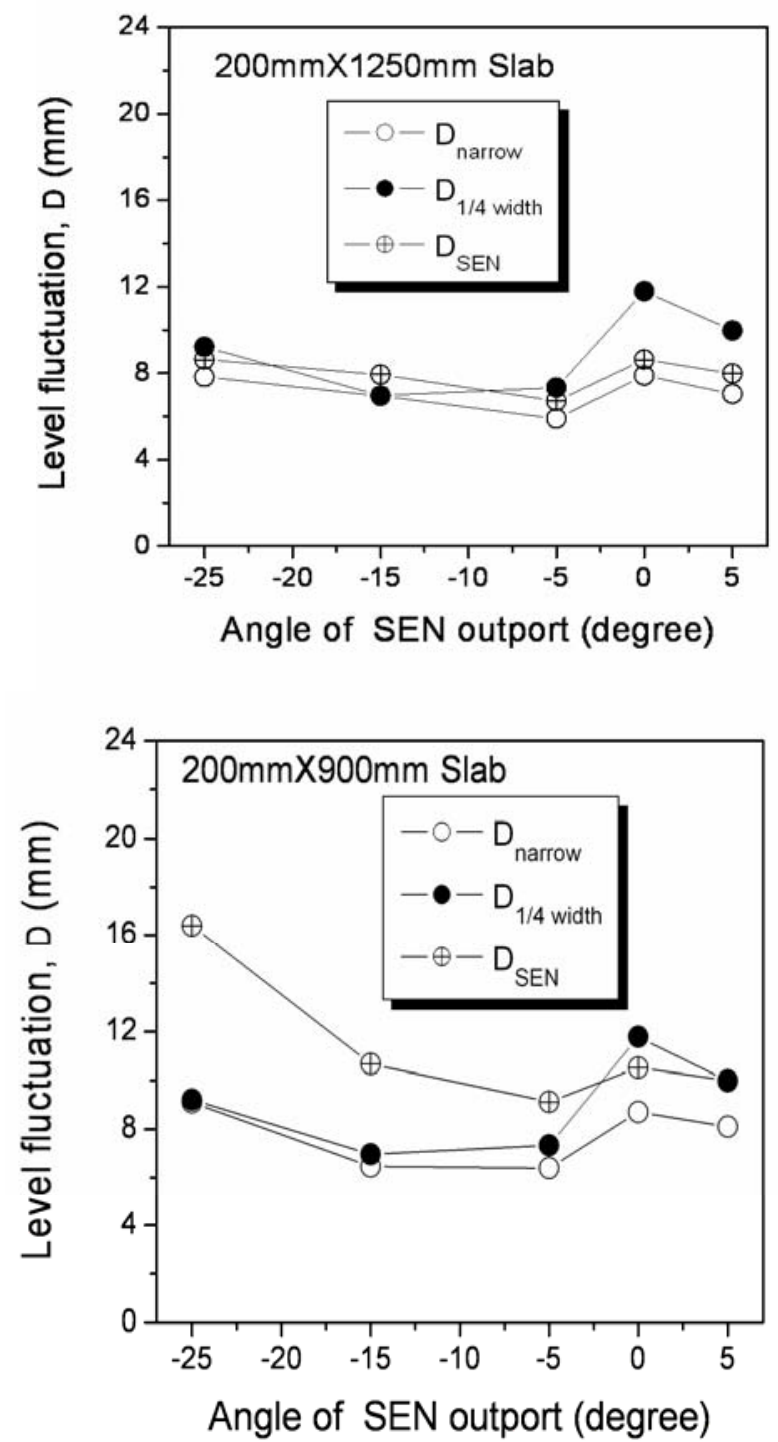

Fig.15 Effect of SEN outport angle on the lwvel fluctuation in the mold 

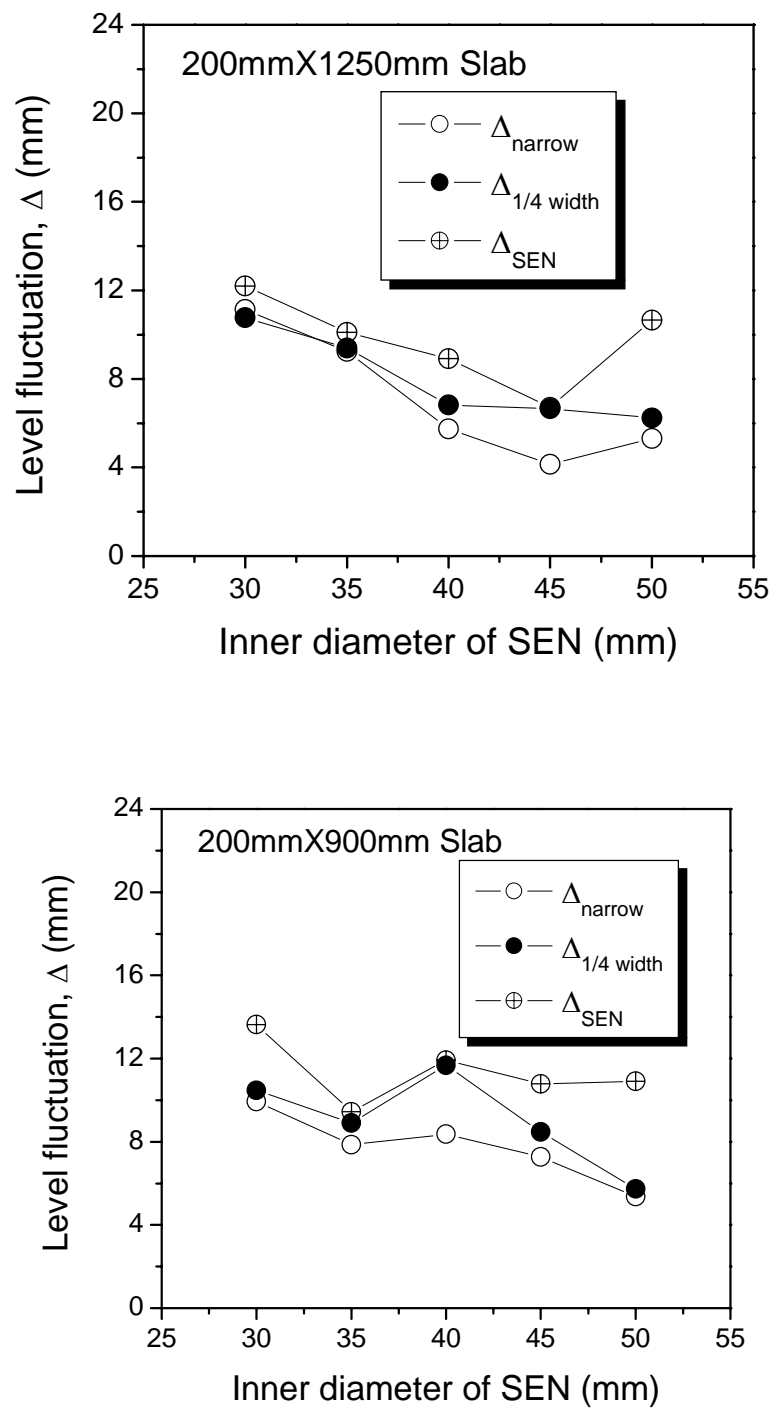

Fig.16 Effect of inner bore diameter of SEN on level fluctuations in the mold 

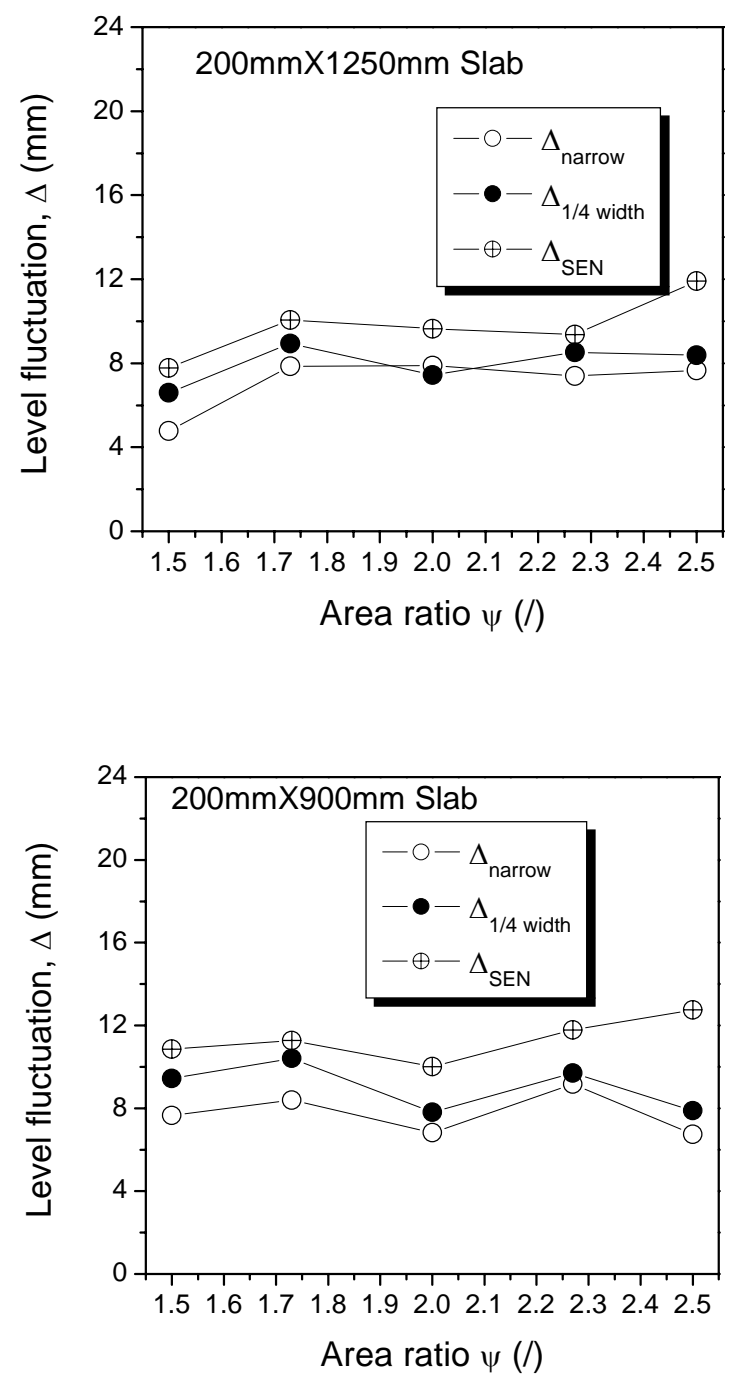

Fig.17 Effect of port-to-bore area ratio $\psi$ on mold level fluctuations 


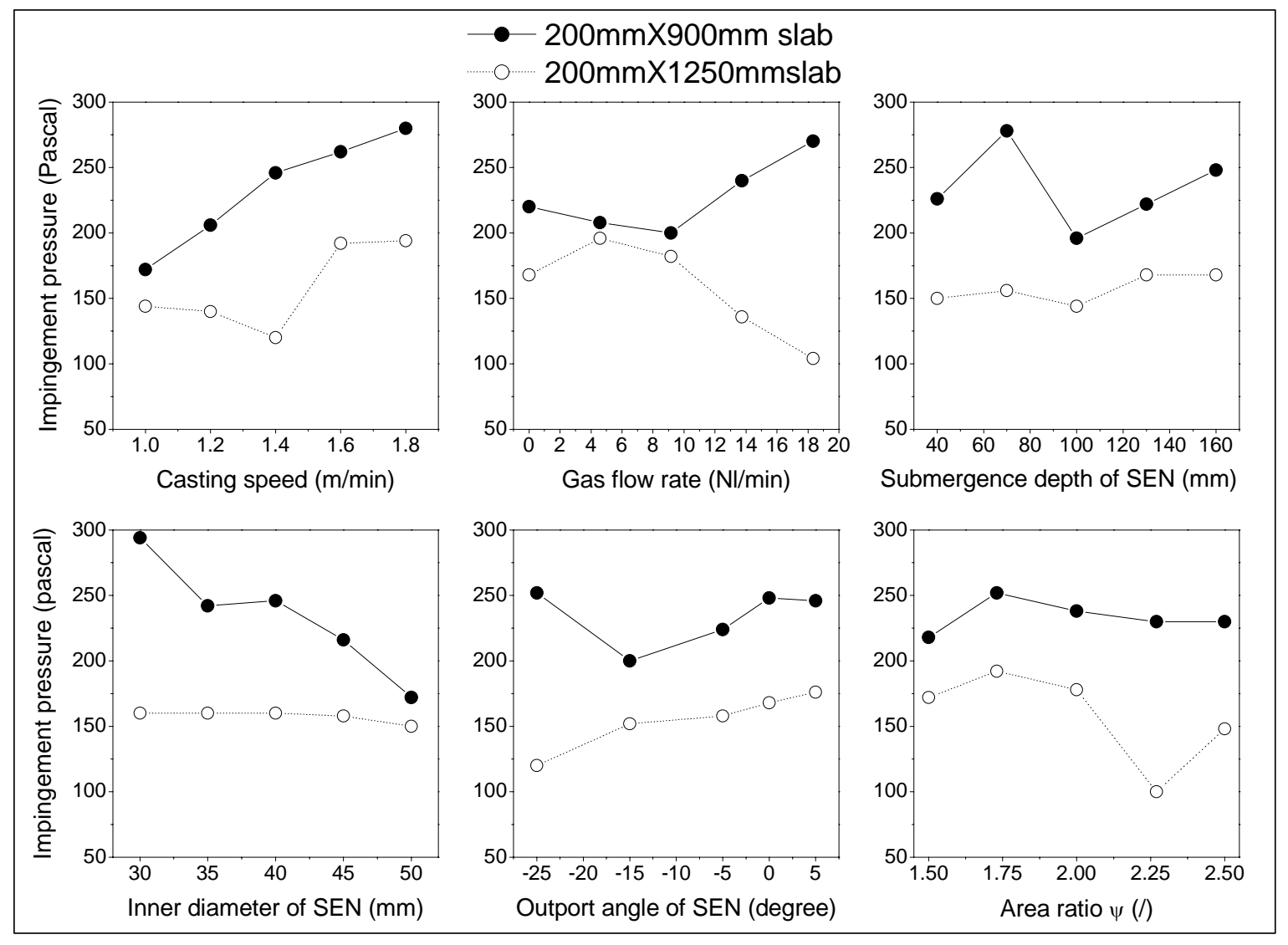

Fig.18 Factors affecting the impingement pressure 


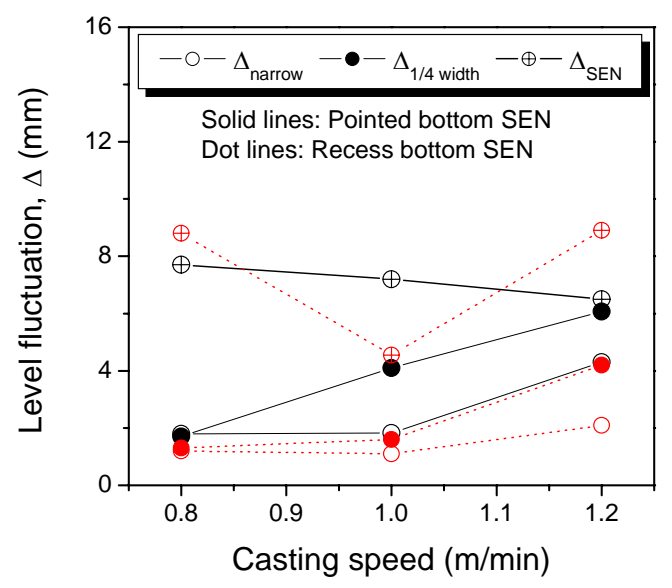

(a)

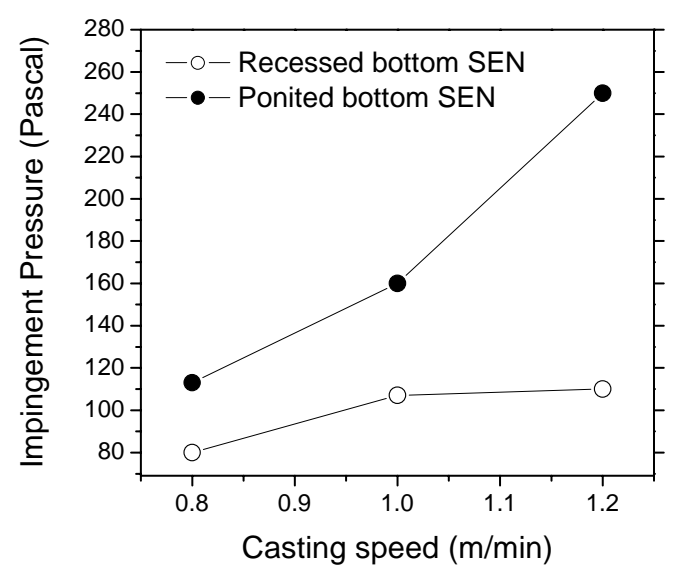

(b)

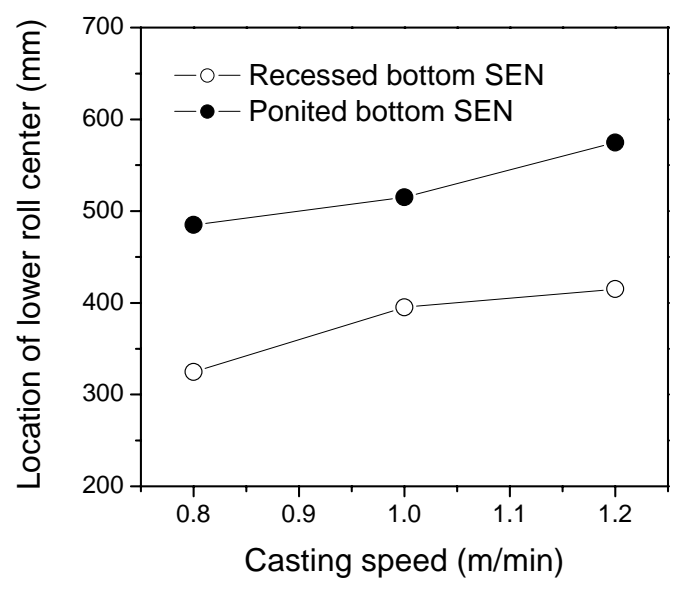

(c)

Fig.19 Measured level fluctuation (a), impingement pressure (b) and the location of the lower roll center (c) with different SEN bottom shape for the water mode of the $200 \mathrm{~mm} \times 1250 \mathrm{~mm}$ steel mold 


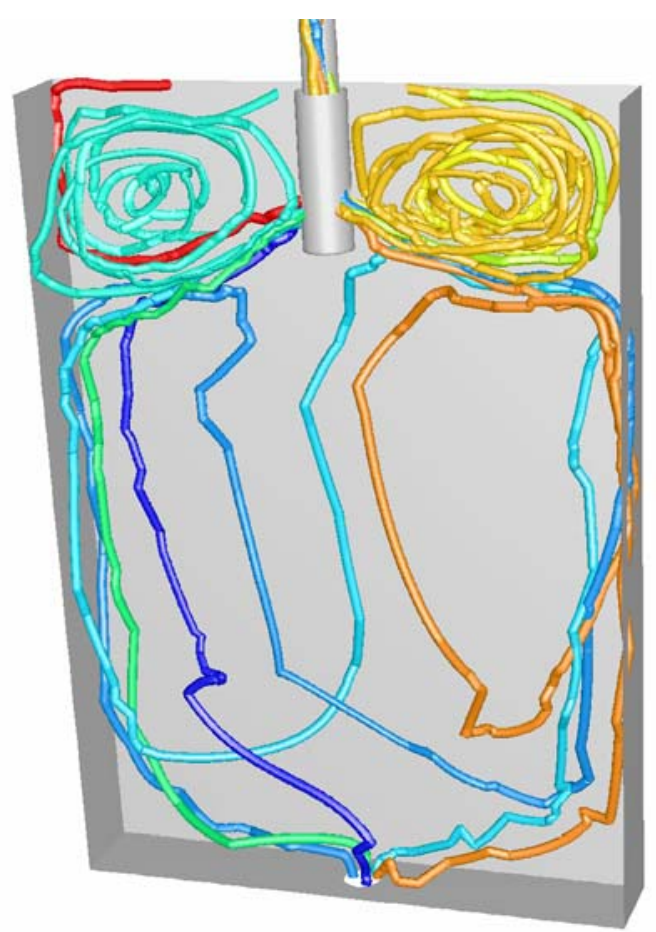

(a)

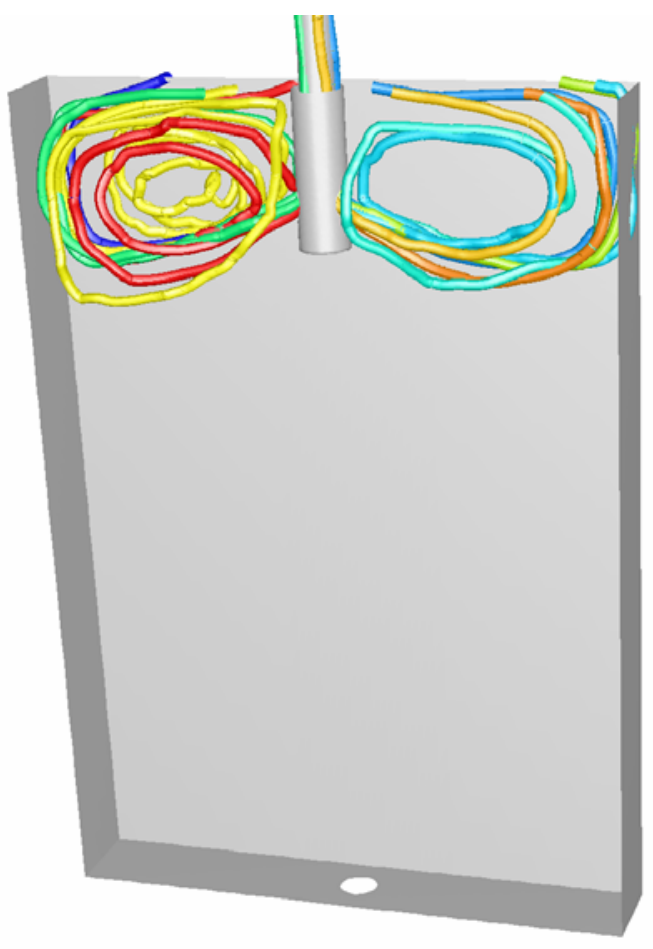

(b)

Fig.20 Typical random walk trajectories of 10 bubbles with the size of $1 \mathrm{~mm}$ (a) and $5 \mathrm{~mm}$ (b) in the water mold of Fig.5 


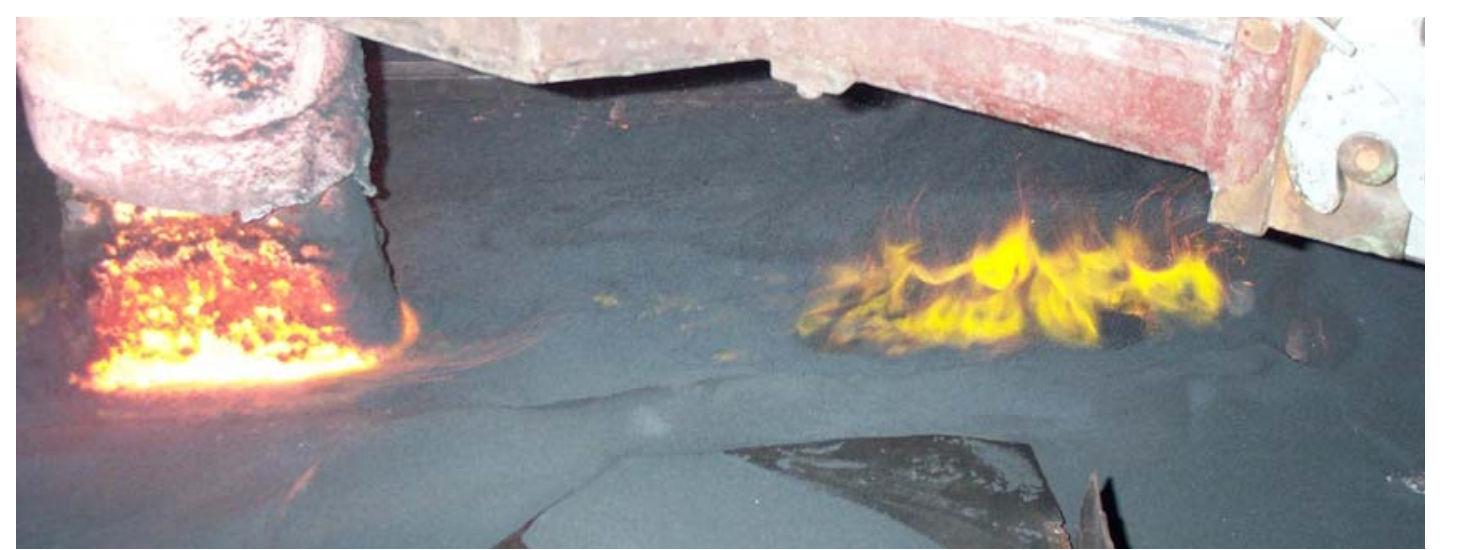

Fig.21 Burning of mold flux at $1 / 4$ width the mold top surface during a slab casting process ${ }^{[113]}$ 

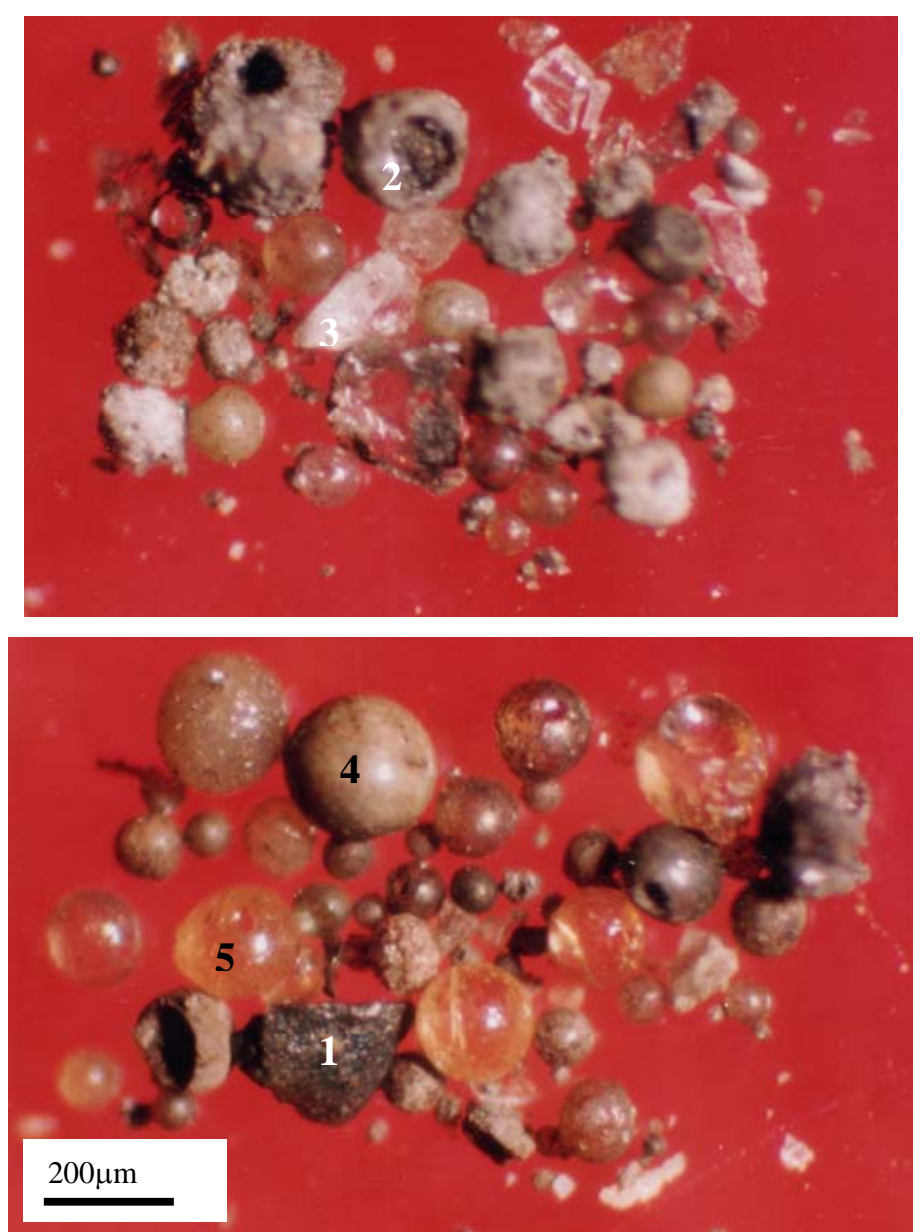

Fig.22 Typical large inclusions in the slab extracted by the Slime method 

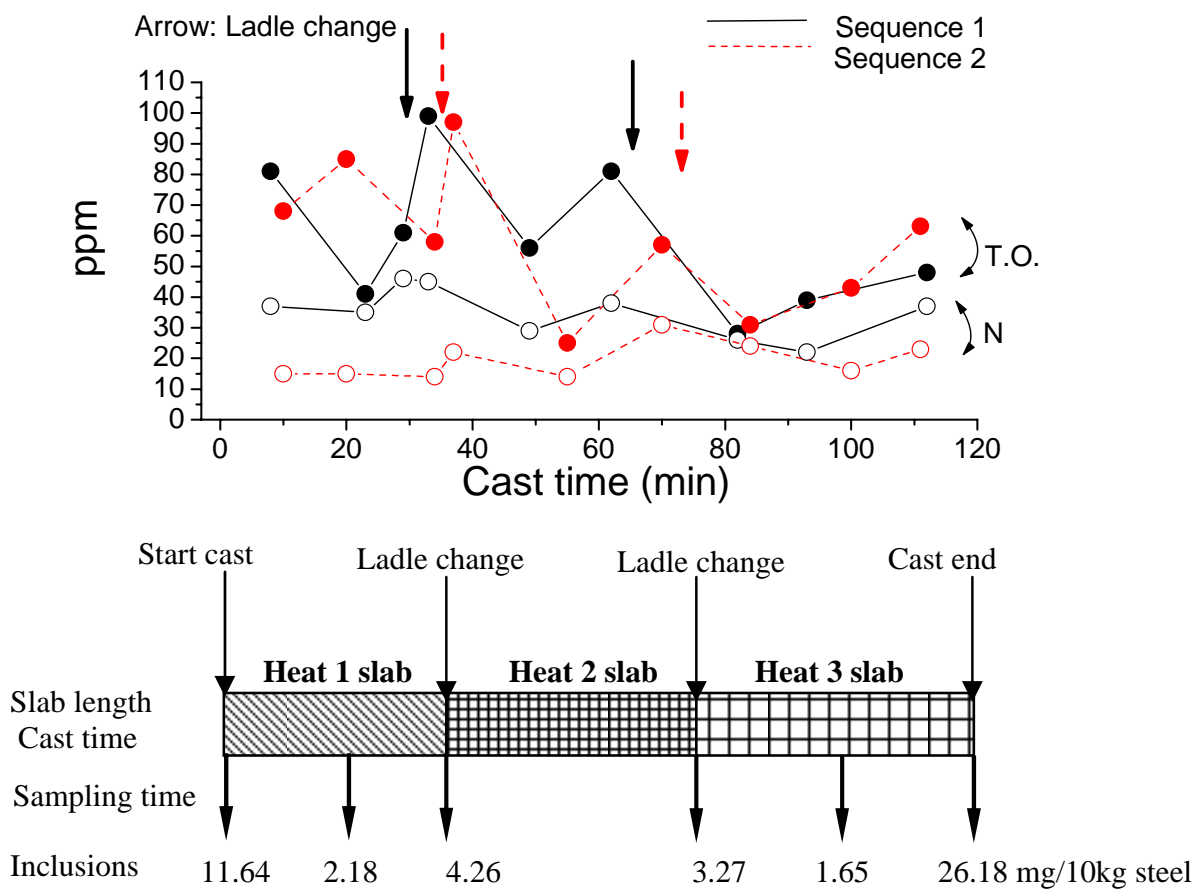

Fig.23 Total oxygen and nitrogen content in the mold (up figure) and $>50 \mu$ m inclusions in the slab by Slime test (lower figure) 